University of Massachusetts Amherst

ScholarWorks@UMass Amherst

Doctoral Dissertations 1896 - February 2014

$1-1-1993$

\title{
The resolution of lexical ambiguity : evidence from an eye movement priming paradigm.
}

Sara Crescentia Sereno

University of Massachusetts Amherst

Follow this and additional works at: https://scholarworks.umass.edu/dissertations_1

\section{Recommended Citation}

Sereno, Sara Crescentia, "The resolution of lexical ambiguity : evidence from an eye movement priming paradigm." (1993). Doctoral Dissertations 1896 - February 2014. 3248.

https://scholarworks.umass.edu/dissertations_1/3248

This Open Access Dissertation is brought to you for free and open access by ScholarWorks@UMass Amherst. It has been accepted for inclusion in Doctoral Dissertations 1896 - February 2014 by an authorized administrator of ScholarWorks@UMass Amherst. For more information, please contact scholarworks@library.umass.edu. 
im

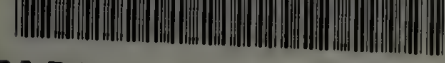

312066 0298 0301?

FIVE COLLEGE

DEPOSITORY 
THE RESOLUTION OF LEXICAL AMBIGUITY:

EVIDENCE FROM AN EYE MOVEMENT PRIMING PARADIGM

A Dissertation Presented

by

SARA CRESCENTIA SERENO

Submitted to the Graduate School of the University of Massachusetts in partial fulfillment of the requirements for the degree of

DOCTOR OF PHILOSOPHY

SEPTEMBER 1993

Psychology 
C Copyright by Sara Crescentia Sereno 1993 All Rights Reserved 
THE RESOLUTION OF LEXICAL AMBIGUITY:

EVIDENCE FROM AN EYE MOVEMENT PRIMING PARADIGM

A Dissertation Presented

by

SARA CRESCENTIA SERENO

Approved as to style and content by:

Keitt hayn

Nitk-Carhon

Neil Carlson, Member

eharles clifton, Member

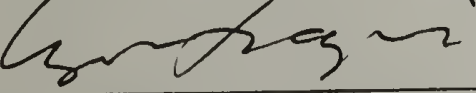

Lyn Frazier, Member

Alepandu Pollatsick

Alexander Pollatsek, Member

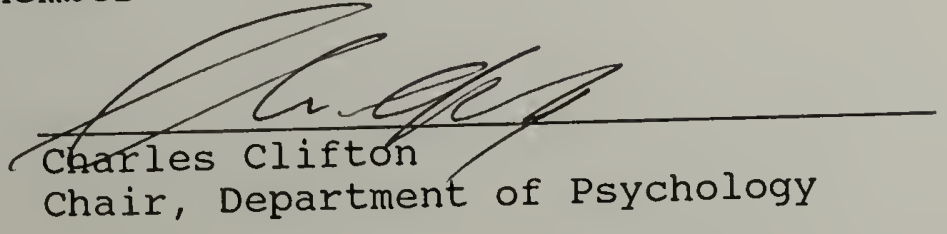




\section{ACKNOWLEDGMENTS}

I wish, first of all, to express extreme gratitude to Keith Rayner for serving as my graduate advisor. Over the years, I found his perspicacity, austere empiricism, and patience -- or rather endurance -- invaluable. He had an eye for promising research directions, yet also gave me freedom to explore my own way. He was extraordinarily fair, except when losing in basketball.

Second, I would like to thank the rest of my committee members. Chuck clifton became an ancillary advisor, providing vigorous intellectual exchange and argument. His profuse generosity in terms of time, technical assistance, and food goodies proved indispensable. Sandy Pollatsek brought keen insights at pivotal moments in my work. Also, his immense knowledge of the Fine Arts certainly kept me on my toes. Lyn Frazier surprised and inspired me with her enthusiasm and discipline, and fostered in me a fresh respect for Linguistics. Neil Carlson was meticulous, steadfast, and thorough in the classroom and was a conscientious member of my committee, contributing a muchneeded Neurophysiological perspective.

Next, I would like to convey appreciation to my cohorts who have been here at UMass during my tenure as a graduate student. In chronological order, I thank Fernanda Ferreira and John Henderson for their Sunday dinners, Chris Young for his honesty, Susan Boyce, Robin Morris, Jim Slotta, and Erika stewart especially for their enduring friendship, 
Mary Lesch for her camaraderie, Jeremy Pacht for his droll conversation and wit, my current officemates Lori Rogg and Martin Fischer, Gary Raney for his good-natured roguery and support, and Tom Greene for his engaging fellowship. I would also like to thank members of the Psychology Department staff for their help and humor, in particular Joanne Daughdrill, Jeanie Sullivan, Joe Bergman, Jon Borden, and Linda Perry.

Finally, I owe the greatest debt to my family. As the youngest of six, whose older siblings have all earned Ph.D.'s, it was my destiny to follow in their footsteps. I graciously thank Anne and Sylvain, Margaret, Joan, Allard, Katrina, and Mark, Paul, and Martin and Claudia. Last, I would especially like to express my love to my parents Rena and Charles for giving me everything they had and providing a vision. 


\begin{abstract}
THE RESOLUTION OF LEXICAL AMBIGUITY:

EVIDENCE FROM AN EYE MOVEMENT PRIMING PARADIGM
\end{abstract}

SEPTEMBER 1993

SARA CRESCENTIA SERENO, B.S., NORTHERN ILLINOIS UNIVERSITY

$$
\begin{aligned}
& \text { M.S., UNIVERSITY OF MASSACHUSETTS } \\
& \text { Ph.D., UNIVERSITY OF MASSACHUSETTS } \\
& \text { Directed by: Professor Keith Rayner }
\end{aligned}
$$

Two experiments investigated how textual context is used to disambiguate lexically ambiguous words. Previous research had suggested that context did not guide access toward the contextually appropriate meaning but instead selected this meaning from multiple activated meanings at a later stage of processing. The experiments reported here developed and used a new technique to explore the very early stages of word recognition. Eye movements were measured during reading. In both experiments a "prime" word was briefly displayed during the initial part of the fixation on the "target" word. Priming was measured by comparing fixation times on targets preceded by semantically Related versus Unrelated primes. Experiment 1 showed significant priming effects at a $35 \mathrm{~ms}$ prime duration but not at 30 or 25 ms prime durations. In Experiment 2, lexically ambiguous words were used as primes to targets in short passages and were presented for $35 \mathrm{~ms}$. The type of preceding context (Consistent vs. Inconsistent), type of ambiguous prime (Biased vs. Balanced), and strength of instantiated meaning 
(Dominant vs. Subordinate) were varied. Only when the preceding context was Consistent with the Dominant meaning of a Biased ambiguous word were significant priming effects obtained. These results supported a model of lexical access in which context does guide access toward the contextually appropriate meaning of an ambiguous word. 
Page

ACKNOWLEDGMENTS

ABSTRACT

LIST OF TABLES

Chapter

I. INTRODUCTION . . . . . . . . . . . . . . . . 1

Priming Paradigms . . . . . . . . . . . 2

The Cross-Modal Task . . . . . . . . . . . . 3

other Methodologies and Some Problems ..... 4

Reinterpretations . . . . . . . . . . . 9

Eye Movements and Lexical Ambiguity Resolution • . 11

Eye Movements Reflect Cognitive Processing . . 12

Eye Movement Studies of Lexical Ambiguity

Resolution . . . . . . . . . . . . 13

An Eye Movement Priming Paradigm . . . . . . 15

Fast Priming . . . . . . . . . . . . . 16

Fast Priming in Reading . . . . . . . . . . 17

The Limits of Fast Priming . . . . . . . . 20

Lexical Ambiguity Resolution and Fast

Priming in Reading . . . . . . . . . 22

II. EXPERIMENT 1 . . . . . . . . . . . . . . 26

Method . . . . . . . . . . . 27

Subjects . . . . . . . . . . . . . 27

Apparatus . . . . . . . . . . . . 28

Materials . . . . . . . . . . . 29

Design . . . . . . . . . . . . . . 29

Procedure . . . . . . . . . . . . 30

Results ........ . . . . . . 33

Discussion . . . . . . . . . . . 36 
III. EXPERIMENT 2 . . . . . . . . . . . . . . . . 39

Method . . . . . . . . . . . . . 42

Subjects . . . . . . . . . . . . 42

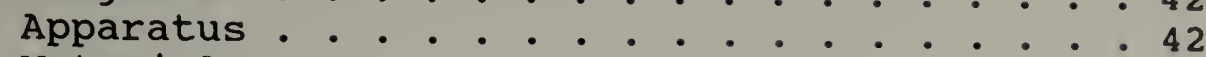

Materials . . . . . . . . . . . . . 42

Design . . . . . . . . . . . . . . . 45

Procedure . . . . . . . . . . . . . . . 46

Results . . . . . . . . . . . . 48

Discussion . . . . . . . . . . . . 51

IV. GENERAL DISCUSSION . . . . . . . . . . . 54

Current Models of Lexical Ambiguity

Resolution . . . . . . . . . . 56

Context and Visual Word Recognition . . . . . 61

APPENDIX: MATERIALS ............... 65

REFERENCES . . . . . . . . . . . . . . . 69 


\section{LIST OF TABLES}

Table

Page

1. Mean First Fixation Duration (ms) on the Target Word in Experiment 1. . . . . . 35

2. Mean Gaze Duration (ms) on the

Target Word in Experiment 1. . . . . . . 35

3. Conditions in Experiment 2 . . . . . . . . . 41

4. Mean First Fixation Duration (ms) on

the Target Word in Experiment 2. . . . . . . 49

5. Mean Gaze Duration (ms) on the

Target Word in Experiment 2. . . . . . . 50 


\section{CHAPTER I}

\section{INTRODUCTION}

Skilled readers rapidly and effortlessly disambiguate a lexically ambiguous word in coherent contexts, usually without much awareness of their inappropriate meanings. Within the domain of language comprehension, a long-running debate about how the lexical processor deals with ambiguity has persisted. Early explanations (e.g., Neisser, 1967) attributed lexical ambiguity resolution to a direct influence of context upon lexical access. Later, more finegrained analyses of language processing raised the possibility that context operates only upon the output of a lexical processor which reports all meanings of a word (e.g., Forster, 1979).

over the past twenty years or so, two opposing camps have emerged. The interactive position (e.g., Mcclelland \& Rumelhart, 1981; Morton, 1969) places few restrictions on the interplay of various processing subsystems during sentence processing. Discourse information, in particular, is hypothesized to play an important role in lexical access. In the processing of an ambiguous word, contextual information is utilized to guide access toward the appropriate meaning. It should be noted that this is not an absolute position. Its proponents do not deny that, at a very early stage, access of both meanings is initiated. An interactive account, however, would hold that the 
appropriate meaning is selected before the word is fully processed (McClelland, 1987).

On the other hand, the modular position (e.g., Fodor, 1983; Forster, 1979) maintains that the operation of lexical access is autonomous with respect to concurrent non-lexical information. No processing within the lexical module can be influenced by extra-lexical knowledge available to another processing subsystem. Because the lexical module is impervious, for example, to the output of a higher-order "message" processor, a biasing sentence context would not prevent the lexical computation of both meanings of a subsequent ambiguous word.

\section{Priming Paradigms}

A number of recent investigations have sought to determine whether context guides the access of the appropriate meaning of an ambiguous word or whether all meanings are automatically accessed with context affecting only later post-access selection processes. These studies have utilized various priming paradigms and will be described in turn. In a priming paradigm, a prime word is normally first presented and then followed (relative to its onset or offset) by a target word. Subjects must respond to the target usually by making a lexical decision (wordnonword response) or by naming it. Response time to the target is the dependent variable. The prime and target can occur experimentally in isolation or in the context of a sentence frame. 
The Cross-Modal Task

Swinney (1979) and Tanenhaus, Leiman, and Seidenberg (1979) both used a cross-modal priming paradigm -- so named because subjects listen to a sentence containing an ambiguous prime and respond to a visual target either by making a lexical decision or by naming it. They examined the activation of contextually appropriate or inappropriate senses of an ambiguous word. The target was presented at various time intervals following offset of the auditory ambiguous word and it was either related to one or the other of its meanings or it was unrelated. At a $0 \mathrm{~ms}$ interstimulus interval (ISI, the time between offset of the prime and onset of the target), responses to targets that were related to the contextually inappropriate as well as the appropriate meaning of the ambiguous word were facilitated compared to the unrelated control. However, when the visual stimulus was delayed for $200 \mathrm{~ms}$ or for several syllables, only the appropriate associate of the ambiguous word was facilitated. From these results they concluded that both meanings of the ambiguous word were initially accessed but, after a short delay, the contextually inappropriate meaning was suppressed.

In a later study using the same technique, seidenberg, Tanenhaus, Leiman, and Bienkowski (1982) did find an advantage for the contextually appropriate sense at a $0 \mathrm{~ms}$ ISI, but it occurred only when the ambiguous word was closely preceded by an associated word. Such a "contextual" 
effect, though, is not regarded as evidence against a modular view because the effect is construed to be intralexical -- that is, originating within the lexicon itself (Forster, 1979). The presence of a prior word related to one sense of an ambiguous word can facilitate access of that meaning through the mechanism of spreading activation, whereby activation from one node in a semantic network spreads to related, neighboring nodes and lowers their recognition thresholds (Collins \& Loftus, 1975; Morton, 1969).

Taken together, the results of these studies and others like them (e.g., Kintsch \& Mross, 1985; Onifer \& Swinney, 1981) have served to establish the modularity of lexical processing as the generally accepted view. By this account, all meanings of an ambiguous word are accessed regardless of the context (except when the context immediately preceding the ambiguous word contains a lexical associate). The terms "multiple" access and "exhaustive" access (referring to the number of meanings initially accessed) have come to be synonymous with the modular position. other Methodologies and Some Problems

Some experimental results, however, suggest that not all meanings of a lexically ambiguous item may be available at very early stages of the word recognition process (simpson \& Burgess, 1985; Simpson \& Krueger, 1991; Tabossi, 1988; Van Petten \& Kutas, 1987). In a unimodal visual lexical decision task, Simpson and Burgess (1985) presented 
subjects with ambiguous word primes followed by target items. Targets were either related to the most frequent (dominant) meaning of the ambiguous prime, related to the less frequent (subordinate) meaning of the prime, unrelated to the prime, or were nonwords. They systematically varied the stimulus onset asynchrony (SOA, the time from onset of the prime to onset of the target) from $16 \mathrm{~ms}$ to $750 \mathrm{~ms}$. At a $16 \mathrm{~ms}$ SOA, only responses to the dominant meaning of the ambiguous primes were facilitated relative to the unrelated control condition. At longer SOAs (e.g., $300 \mathrm{~ms}$ ), both the dominant and the subordinate meanings of the ambiguous primes were facilitated, while at even longer SOAs (e.g., $750 \mathrm{~ms})$, only the dominant meaning was again facilitated. Simpson and Burgess concluded that the relative frequency of the respective meanings played an important role in the time course of lexical activation.

Using the traditional cross-modal technique, Tabossi (1988) found that access of only the dominant meaning of a lexically ambiguous item can take place when the ambiguity is embedded in a highly constraining sentential context. If the context places sufficient constraints on the ambiguous word, then access of only the contextually appropriate meaning occurs. Thus, the nature of the information available in the prior sentence context is crucial to the interpretation of cross-modal results.

The results of Van petten and Kutas (1987) also call into question the interpretation of lexical ambiguity 
resolution inspired by the earlier studies. Van Petten and Kutas used a procedure similar to that of the early crossmodal studies except that the sentential context as well as the targets were presented visually and subjects were required to name targets. Two different SOAs $(200 \mathrm{~ms}, 700$ ms) were used. Their first experiment produced data comparable to the classic cross-modal results -- that is, both contextually appropriate and inappropriate meanings of the ambiguous word were facilitated at the $200 \mathrm{~ms}$ SOA versus an unrelated control, but only the contextually appropriate meaning was facilitated at the longer $700 \mathrm{~ms}$ SOA. In their second experiment, they recorded event related potentials (ERPs), using the identical stimulus materials of the first experiment. A different pattern of results emerged. At the $200 \mathrm{~ms}$ SOA, the N400 component of the wave form (considered to be sensitive to semantic anomalies) indicated that the response to contextually appropriate targets diverged from the unrelated target response $200 \mathrm{~ms}$ prior to the divergence of the contextually inappropriate target response. Although the naming latencies of the first experiment had suggested that both contextually appropriate and inappropriate meanings were simultaneously activated, the ERP measures (which are more temporally sensitive in that they produce a continuous record) indicated a significantly later onset for contextually inappropriate meanings.

A recent study by Simpson and Krueger (1991) also questions the cross-modal results. Simpson (1981) earlier 
had found priming to only the appropriate sense of an ambiguous word in a cross-modal lexical decision task using strongly biasing contexts and a $120 \mathrm{~ms}$ ISI. In Simpson's (1981) experiment, a lexical decision task was used which is susceptible to response bias and may thus reflect postlexical integration rather than lexical access effects (Balota \& Chumbley, 1984) and the target may have been primed by the context instead of the ambiguous word prime. Simpson and Krueger (1991) performed two experiments designed to resolve these problems. In the first experiment, subjects named a target which appeared at various offsets after they finished reading aloud a sentence which ended with an ambiguous prime. In strongly biasing contexts at all offsets (which were determined by the experimenter who, upon hearing the subject utter the ambiguous prime, pressed a button causing the target to appear either immediately or at a delay of 300 or $700 \mathrm{~ms}$ ), they found priming only to the contextually appropriate sense (dominant or subordinate) of the ambiguous word. In their second experiment, simpson and Krueger (1991) tested whether context itself produced the results. They substituted words unrelated to the targets for each ambiguous prime but found no effects of priming.

Together, these studies point out the importance of strict observance of the time course of processing in lexical ambiguity research as well as the need to carefully control sentence context. In some cases (e.g., Simpson, 
1981; Van Petten \& Kutas, 1987), the results of these studies have been used to support an interactive position whereby prior context mediates the "selective" access of the appropriate sense of an ambiguous word. In other cases (e.g., Simpson \& Burgess, 1985), the focus has been on the potential influence of the dominance relationship among the alternative senses of an ambiguous word.

Simpson and others have offered an "ordered" access model to account for the effects of meaning dominance (Hogaboam \& Perfetti, 1975; Simpson, 1981, 1984). In this model, the alternative senses of an ambiguous word are accessed in order of their dominance or meaning frequency. The issue of meaning dominance and access is somewhat orthogonal to the interactive versus modular or selective versus multiple access debate. In the strictest interpretation, selective access implies that only the contextually appropriate sense is accessed (although multiple senses may be initially activated) and multiple access implies that all meanings are always accessed and become available in parallel. Both the interactive and modular account, however, are seemingly able to incorporate the meaning dominance aspect of ambiguous words into their respective models. Under these slightly modified interpretations, the initial activation of the alternative senses of an ambiguous word as well as the subsequent access of one (selective access) or both (multiple access) of its senses would be staggered in order of their relative 
frequency. In such a case, perhaps a more descriptive term for selective access might be "guided access with multiple activation" and a better term for multiple access "sequential access within a small temporal window". Reinterpretations

The criticism of the cross-modal results that has received the most attention concerns its methodology. Glucksberg, Kreuz, and Rho (1986) contend that the technique is compromised by reciprocal or backward priming effects. The pivotal argument here is that priming of the contextually inappropriate sense of the ambiguous word may be more an artifact of secondary priming than a result of autonomous access -- the target activates the contextually inappropriate sense of the ambiguous word which, in turn, forwardly primes the target itself. Earlier, Meyer and Schvaneveldt (1971) demonstrated in a lexical decision task that responses to simultaneously presented visual word pairs were facilitated when the words were related. For example, the word pair nurse-doctor elicited a faster response than nurse-bread. Kiger and Glass (1983) also found that an associative visual prime could follow a target by $50 \mathrm{~ms}$ and still produce a significant (99 ms) advantage in lexical decision. It should be noted that Burgess, Tanenhaus, and Seidenberg (1989; see also Prather \& Swinney, 1988) have presented contrary data and strong arguments against Glucksberg et al.'s (1986) findings for a backward priming explanation of the cross-modal ambiguity results. 
Nevertheless, until backward priming effects are definitively shown not to be a factor, methodologies that substantially minimize or eliminate potential backward priming effects should be favored when possible.

McClelland (1987) took a different approach in his criticism of the cross-modal results (see also st. John, 1991, for a similar, more comprehensive treatment) . He examined the results of the experiments reported in swinney (1979), Tanenhaus et al. (1979), and Seidenberg et al. (1982). All of these experiments had shown evidence for multiple access in a 0 ISI condition (i.e., when the visual target immediately followed offset of the auditory prime). MCClelland (1987) took an average of the priming effects for appropriate targets and compared it to the average of priming effects for inappropriate targets. He found that overall there was an advantage for the appropriate primes. That is, the priming effects were larger when the target was related to the contextually biased sense of the ambiguous word. In fact, this is what Van Petten and Kutas (1987; see above) also found in their first experiment: Naming time to control words was the longest, followed by targets related to the inappropriate meaning, followed by targets related to the appropriate meaning.

A further criticism of the cross-modal experiments also concerns its methodology. Because it is a cross-modal task - - consisting of an auditory context up to and including the ambiguous prime, followed by a visual target 
requiring an explicit response, followed (in most cases) by the rest of the auditory sentence -- severe attentional demands are placed on the subject by the requirement to switch modes and respond to a visual target. It may be that only the last one or two words of the auditory context are preserved in articulatory rehearsal upon presentation of the visual target. In this circumstance, the subject could be responding to the visual target on the basis of very little contextual information. Thus, multiple access may actually reflect context-free priming. That is, both the appropriate and inappropriate meanings are facilitated because context has been suspended temporarily.

one final caveat has to do with possible misleading terminology. In the cross-modal task, a $0 \mathrm{~ms}$ ISI between auditory prime and visual target imparts a sense of cleancut on-line succession. The reality is that the auditory word may often be recognized before its offset (MarslenWilson \& Welsh, 1978). Meanwhile, responses to the visual target (e.g., Swinney, 1979) take anywhere from two to four times longer than actual fixation times on comparable words in ordinary reading for comprehension (Rayner \& Pollatsek, 1989).

Eye Movements and Lexical Ambiguity Resolution

In the past few years several eye movement studies have investigated lexical ambiguity, attempting to tease apart lexical from post-lexical contextual effects (Dopkins, Morris, \& Rayner, 1992; Duffy, Morris, \& Rayner, 1988; 
Rayner \& Duffy, 1986; Rayner \& Frazier, 1989; Rayner, Pacht, \& Duffy, 1993; Sereno, Pacht, \& Rayner, 1992). In these studies, subjects read sentences containing ambiguous words as their eye movements are monitored. Fixation time on the ambiguous word (the target) as well as fixation time in other regions of the sentence (e.g., the disambiguating region when it follows the target) are examined.

\section{Eye Movements Reflect Cognitive Processing}

It is well-documented that the processing of a word is reflected in its fixation time (for a recent review, see Rayner \& Sereno, 1993). Rayner and Duffy (1986), for example, showed that fixation time is strongly influenced by word frequency (see also Rayner, Sereno, Morris, Schmauder, \& Clifton, 1989). The predictability of a word in a sentence context also influences fixation time (Balota, Pollatsek, \& Rayner, 1985; Erhlich \& Rayner, 1981; Inhoff, 1984; Schustack, Erhlich, \& Rayner, 1987; Zola, 1984). Readers tend to fixate words that are not predictable from a context approximately 30 to $90 \mathrm{~ms}$ longer than predictable words. Additionally, predictable words are more often skipped. However, it is unclear whether these effects should be attributed to lexical access or to post-access processes.

To interpret fixation duration effects properly, it is necessary to specify what mechanism determines when the eyes move. A model of eye movement control proposed by Morrison (1984) claims that attention moves forward from word to 
word, with the eyes following at some prespecified interval. The decision to move attention is dependent upon lexical access of the fixated word. Sereno (1992) and others (e.g., Pollatsek and Rayner, 1990) have argued that various phenomena, including the occurrence of multiple fixations on a single word, demonstrate that Morrison's model is incomplete. Nonetheless, the model's core assumption, that lexical access serves as the trigger for eye movements in fluent reading, remains largely unchallenged. Eye Movement Studies of Lexical Ambiquity Resolution In the eye movement ambiguity studies, four aspects or dimensions of the stimulus materials have been manipulated to determine the critical spatial and temporal loci of contextual influence. The context in which an ambiguous word appears is the first aspect: Disambiguating information can precede the ambiguous word (biasing context) or follow it (neutral context). The second aspect concerns the ambiguous word itself: Some ambiguous words are balanced, having two equally likely meanings (and, possibly, other subordinate senses), but most are biased, having one highly dominant sense and one or more subordinate senses. The third factor that can be varied is the meaning instantiated by the context: It can be the more frequent, dominant meaning or the less frequent, subordinate one. The fourth consideration is the type of control word that is used. Rayner and Frazier (1989) used an ambiguous word as its own control (the same word appeared in two different 
contexts). More typically, comparisons are made between an ambiguous word and an unambiguous control word when both words fit equally well into a single sentence frame. The control word must also be matched for word length and word frequency. Specifically, the frequency of the control word may be matched either to the overall word form frequency of the ambiguous word (e.g., Duffy et al., 1988; Rayner \& Duffy, 1986) or to the frequency of the instantiated meaning (e.g., Sereno et al., 1992).

The results of these experiments investigating lexical ambiguity resolution have clarified many issues relevant to lexical processing and the role of context, but much remains unresolved in this very complex area (for reviews, see Pacht \& Rayner, 1993; Sereno et al., 1992). Although the data are quite consistent across eye movement studies, two different models have been proposed to account for the findings: the reordered access model (Duffy et al., 1988) and the integration model (Rayner \& Frazier, 1989). In the reordered access model, the alternative senses of an ambiguous word are initially activated in order of their relative frequencies ${ }^{1}$. Contextual information can influence the activation of the appropriate sense and,

${ }^{1}$ Access of alternative meanings in the reordered access odel is ordered but not strictly serial. It is necessary to assume that multiple meanings are active at the same time to account for effects of competition among meanings. The model merely assumes that different meanings become available at different times, not that only one meaning can be active at once. 
accordingly, reordered access resembles a selective access account. If context supports the subordinate sense, for example, this "boosts" the activation of the subordinate sense relative to the dominant sense and thus reorders access procedures.

In the integration model, initial activation is ordered as well. To preserve modularity, context only influences the output of the lexical processor in a post-lexical integration stage. Successful integration of one sense automatically terminates incomplete access procedures. Because the alternative senses are accessed sequentially, it may be the case, for example, that the subordinate sense is never fully accessed when context instantiates the dominant sense. Although the reordered access and integration models differ in terms of when context influences processing, both are presently able to account for the data. The locus of contextual effects, whether lexical, post-lexical, or both, thus remains undetermined from this research.

\section{An Eye Movement Priming Paradigm}

As mentioned above, the main purpose of the early cross-modal studies was to determine whether all meanings of an ambiguous word are retrieved at once and whether the retrieval process is sensitive to context effects. Lexical priming to a target related to a particular meaning of an ambiguous word was utilized to provide evidence that the meaning was activated. Thus, it was necessary to locate the target as close as possible in time to the moment of access 
of the meaning or meanings of the prime. This was attempted through the use of a $0 \mathrm{~ms}$ ISI between the auditory prime and the visual target. To achieve more accurate results in a same-mode visual paradigm, the present study uses ambiguous words as primes in the "fast priming" paradigm developed by Sereno and Rayner (1992). In this paradigm, the prime word is presented foveally at the onset of an eye fixation while subjects are reading. After a brief exposure, the prime is replaced by the target. Fixation time on the target is the dependent variable.

The eye movement technique offers several advantages as an alternative methodology in lexical priming studies of ambiguity. First, the eye fixation measure itself has a much shorter latency than either lexical decision or naming. Because decision time is reduced, there is also much less opportunity for possible backward priming effects. In addition, the same-mode (visual) presentation permits more accurate control over the time course of processing the prime and target.

Fast Priming

Only a few studies have examined associative priming effects using both a short SOA and a $0 \mathrm{~ms}$ ISI in the visual mode (Fischler \& Goodman, 1978; Sereno, 1991; Warren, 1977). Warren (1977) presented a prime word for $75 \mathrm{~ms}$ above a fixation point. The prime was then masked and, simultaneously, the target, which was to be named, appeared below the fixation point. There was a significant $14 \mathrm{~ms}$ 
advantage for "synonym" primes versus an unrelated condition. Using a lexical decision task, Fischler and Goodman (1978) presented a prime word for $40 \mathrm{~ms}$ which was immediately replaced by a target item in the same location (masking the prime). Word primes were equally divided between "associated" and "unrelated" types. Associated primes produced a significant $41 \mathrm{~ms}$ facilitation. Sereno (1991) used a three-field masking paradigm (devised by Forster \& Davis, 1984). A prime word was displayed for 60 ms, preceded (and forward masked) by an unrelated word, and followed (and backward masked) by a target word (all ISIs were $0 \mathrm{~ms})$. Significant associative priming effects were obtained in lexical decision (41 ms) but not in naming ( 7 ms) .

\section{Fast Priming in Reading}

Sereno and Rayner (1992) investigated fast, associative priming effects at a single foveal location within a single fixation in reading using eye movement techniques. In their procedure, subjects read sentences while their eye movements were monitored. The time course of events that occurred while a subject read a sentence is depicted below:

\section{*-*-----*--------*---}

(1) Tight quarters produce!d gzsd and discord.

(2) Tight quarters produce! $\mathrm{d}$ love and discord.

(3) Tight quarters produce!d hate and discord.

(4) Tight quarters produce!d hate and discord. 
In (1), when the eyes were to the left of the invisible boundary (indicated by 1 ), a preview of random letters (gzsd) occupied the target position. During the saccade that crossed the boundary, the prime (love) replaced the preview for a designated time (2). The target (hate) then replaced the prime (3) and remained in place while the subject finished reading the sentence (4).

Sereno and Rayner (1992) used a preview of random letters to prevent parafoveal preprocessing of the prime. It has been shown that parafoveal information does influence eye fixation durations (Balota et al., 1985; Blanchard, Pollatsek, \& Rayner, 1989; Inhoff \& Rayner, 1986; Pollatsek, Lesch, Morris, \& Rayner, 1992; Rayner, 1975). Information about initial letter sequences, for example, speeds the (later) lexical processing of the parafoveal word while the semantic content of the parafoveal word is not effective in doing so (Rayner, Balota, \& Pollatsek, 1986).

In their first experiment, Sereno and Rayner (1992) used prime durations of 30,45 , and $60 \mathrm{~ms}$. The prime was either semantically related to the target (love), semantically unrelated (rule), or identical (the target hate was presented from the onset of the fixation). They examined the gaze duration on the target (i.e., the sum of all fixations on that word before a saccade was made to a different word). They found a $28 \mathrm{~ms}$ priming advantage for related (R) versus unrelated (U) primes at the $30 \mathrm{~ms}$ prime duration level and no difference between $R$ and $U$ conditions 
at either the $45 \mathrm{~ms}$ or $60 \mathrm{~ms}$ prime durations. Differences between the identical (I) and $R$ conditions and the $I$ and $U$ conditions at every level of prime duration were all significant or marginally so with one exception. The average difference in these contrasts was $-35 \mathrm{~ms}$, suggesting that the presence of a nonidentical prime produced a disruptive effect. The exception was at the $30 \mathrm{~ms}$ prime duration (which exhibited a semantic priming effect). There was a nonsignificant $-5 \mathrm{~ms}$ difference between the $I$ and $R$ conditions -- the priming facilitation seemingly offset the disruptive presence of a nonidentical prime.

In their second experiment, Sereno and Rayner (1992) further explored the priming function around the $30 \mathrm{~ms}$ prime level using prime durations of 21,30 , and $39 \mathrm{~ms}$. Again, they used $R$ and $U$ primes. In place of the I prime condition, however, they used a random letter string (RLS) prime condition as a baseline to measure disruptive effects. They found a $31 \mathrm{~ms}$ priming advantage for $R$ versus $U$ primes at the $30 \mathrm{~ms}$ prime duration level, replicating the results of the first experiment. Differences between $R$ and $U$ prime conditions at the 21 or $39 \mathrm{~ms}$ prime levels were not significant, nor were differences between the $R$ and RLS or the $U$ and RLS conditions. Gaze duration in the RLS condition increased as prime duration increased, suggesting greater disruption, but these differences were not significant. 
Sereno and Rayner (1992) explained their main result -semantic priming only at the $30 \mathrm{~ms}$ prime duration -- by an interaction of forward and backward effects that simultaneously affected processing. Forward effects were identified as (1) priming and (2) disruption (forward masking). The source of backward effects was the target itself which masked the prime. The effectiveness of a target used as a mask depends on its relationship to the prime. Masks that are similar to their primes, for example either visually (Jacobson, 1974) or phonetically (Perfetti, Bell, \& Delaney, 1988), are less effective. Sereno and Rayner (1992) suggested that the target-masks which were semantically similar to their $\mathrm{R}$ primes also proved to be less effective as masks. Also, as prime duration increased from the $30 \mathrm{~ms}$ level, it may have been the case that priming decreased as the perceptual threshold was approached -- that is, the $30 \mathrm{~ms}$ duration may have fallen in a narrow nearthreshold region within which priming effects are more easily obtained (cf. Dagenbach, Carr, \& Wilhelmsen, 1989). Regardless of the theoretical resolution to the overall pattern of results, significant priming was demonstrated at the $30 \mathrm{~ms}$ prime duration level (a $28 \mathrm{~ms}$ effect in the first experiment) and this was replicated (a $31 \mathrm{~ms}$ effect in the second experiment).

The Limits of Fast Priming

As noted, Sereno and Rayner (1992) found semantic priming effects using the fast priming paradigm when the 
prime word was presented for $30 \mathrm{~ms}$. Primes presented for less than $30 \mathrm{~ms}$ were ineffective. The sensory input from a word presented for less than $30 \mathrm{~ms}$ (and followed by a target-mask) may be insufficient to be of much consequence. Rayner, Inhoff, Morrison, Slowiaczek, and Bertera (1981; see also Ishida \& Ikeda, 1989) examined reading when the text was masked at various intervals after a fixation $(10,30$, 50, 100, or $150 \mathrm{~ms}$ after the onset of the fixation). They found that reading was near normal when the text was available for $50 \mathrm{~ms}$. When the text was available for only $30 \mathrm{~ms}$, reading performance was impaired, and it was very poor when the text presentation was for only $10 \mathrm{~ms}$.

Primes presented for longer than $30 \mathrm{~ms}$ were also ineffective. This upper prime duration limit is constrained by two factors. First, the prime cannot be so long as to be mistaken for part of the on-going sentence. That is, in normal reading, some level of word activation is reached (after about 75 - $100 \mathrm{~ms}$ ) which triggers the programming of an eye movement to a following word (Morrison, 1984). Second, a prime presented for 40 to $60 \mathrm{~ms}$ may become active enough to compete with the activation and subsequent access of the target, and a reader may even become consciously aware of a prime presented for such a duration.

Thus, what is left between these two limits is a window of prime durations (from about 30 to $40 \mathrm{~ms}$ ) where priming is possible (i.e, the meaning gets through and spreads 
activation, but the form is effectively masked by the target).

Lexical Ambiguity and Fast Priming in Reading

The present study was designed to study the resolution of lexical ambiguity using the eye movement fast priming technique described above. As in the experiments reported by Sereno and Rayner (1992), a boundary and a preview of random letters are used to prevent parafoveal preprocessing. $R$ and $U$ primes are also used with one modification -- they are lexically ambiguous words. The possibility of intralexical priming from a nearby semantic associate is eliminated by distancing the prime from its context (Foss, 1982). Consider the following sentences:

(5) The thief came in the middle of the night. Fortunately, our (bark)dogs were alert.

(6) The thief came in the middle of the night. Fortunately, our (cast)dogs were alert.

(7) Many elms showed signs of the disease. with luck, our (bark)tree would survive.

(8) Many elms showed signs of the disease. with luck, our (cast) tree would survive.

(9) Many elms showed signs of the disease. Fortunately, our (bark)dogs were alert.

(10) Many elms showed signs of the disease. Fortunately, our (cast)dogs were alert.

(11) The thief came in the middle of the night. With luck, our (bark)tree would survive.

(12) The thief came in the middle of the night. with luck, our (cast) tree would survive.

The first sentence in each sentence pair (or passage) is a context sentence favoring one of two senses of an 
ambiguous word. The second sentence is a test sentence which is either congruous (passages 5, 6, 7, and 8) or incongruous (passages 9, 10, 11, and 12) with regard to the preceding context. Test sentences contain a primed target (the prime appears in parentheses). The prime in odd numbered passages (bark) is semantically related (R) to its subsequent target (dogs or tree), while the prime in even numbered passages (cast) is unrelated (U). The U prime serves as a control for the $\mathrm{R}$ prime: It is also an ambiguous word and has a similar overall word frequency as the $\mathrm{R}$ prime as well as a similar frequency relationship among its alternative meanings. Each meaning of the ambiguous word is paired with a context and test sentence. The task for the subject is to decide whether the two sentences "go together" (congruous) or "don't go together" (incongruous). The appropriate context sentence for one sense of the ambiguous word is exchanged with the appropriate context sentence for the other sense in order to produce the incongruity. Because the $R$ prime is ambiguous, switching context sentences gives rise to a situation in which one sense of the $\mathrm{R}$ prime is related to the prior context while its other sense is related to the subsequent target (passages 9 and 11 ).

It is expected that a priming effect (the difference between $R$ and $U$ conditions) on a target will be observed when a congruous biasing context is presented (i.e., 5 vs. 6,7 vs. 8). Such an effect can be explained either by a 
selective access or multiple access account, but for different reasons. According to the selective access account, priming occurs because the context sentence activates the appropriate meaning of the ambiguous $R$ prime which, in turn, primes the target. Under a multiple access account, the context sentence is inconsequential at an early stage. Both senses of the $R$ prime would be activated at a short SOA in any case and could thus prime either an appropriate or inappropriate target.

An incongruous biasing context (i.e., 9 vs. 10, 11 vs. 12) serves to distinguish the selective access and multiple access accounts. Selective access now predicts that priming of the target will fail and may even produce an inhibitory effect since the wrong sense of the $R$ prime is accessed. Multiple access predicts that priming of the target will occur just as in the congruous condition since the presence or absence of a biasing context is irrelevant.

In sum, the goal of this experiment is to produce a definitive answer about lexical processing (selective vs. multiple access) at the critical initial stage of lexical ambiguity resolution. The prospect that a brief visual probe can be presented precisely at the initial moment of access of a target and a response elicited almost instantly upon completion of access offers an opening to dispel uncertainty about the temporal loci of events and the role of decision bias in existing paradigms. 
Finally, the research of Sereno and Rayner (1992) had established that a prime duration of $30 \mathrm{~ms}$ reliably yielded priming effects. In the interim, an equipment change occurred. A new high-speed monitor replaced the CRT used in the previous study. Results from that study indicated that priming effects were confined to a relatively narrow temporal window. In view of this sensitivity, it was thought prudent to re-establish an optimum prime duration with the new equipment. This was the goal of Experiment 1. 


\section{CHAPTER II}

\section{EXPERIMENT 1}

Experiment 1 was designed to determine whether fast automatic semantic priming effects could be obtained using the materials from Sereno and Rayner (1992) under a different text presentation system. In addition to a different monitor and computer, a few minor modifications in experimental design were made. These modifications are incorporated into the representation of the experimental paradigm illustrated below (the pattern of fixations and saccades is identical to the example in the Introduction):

(13) Tight quarters producedi tidn and discord.

(14) Tight quarters produced $\stackrel{--*}{\text { love }}$ and discord.

(15) Tight quarters produced ${ }^{*}$ hate and discord.

(16) Tight quarters produced hate and discord. First, Sereno and Rayner (1992) had used three different prime conditions -- related (R), unrelated (U), and identical (I) in Experiment 1; R, U, and random letter string (RLS) in Experiment 2. In this experiment only $R$ and $\mathrm{U}$ prime conditions were used. With only two prime conditions, it was possible to obtain more observations per condition in the comparison of most interest. Second, the position of the invisible boundary ( $i$ ) was established to be between the last letter of the word before the target and the space before the target. This is one character to the 
right of the position used in Sereno and Rayner (1992). In that study, trials in which subjects fixated the last letter of the word before the target (triggering display changes while fixation was not directly on the target) were discarded. With the boundary relocation, such trials were now salvaged. Third, the preview of random letters occupying the target location (e.g., tidn) before the eyes moved to the target differs from that used by sereno and Rayner (1992). Four- and five-letter random letter strings were generated for each target based on the probability that a given letter appears in a given letter position of fourand five-letter words, respectively (Mayzner \& Tresselt, 1965). This produced random letter string previews that were more "word-like" than the ones used in sereno and Rayner (1992). Finally, as before, three prime durations were chosen. Prime durations of 35,30 , and $25 \mathrm{~ms}$ were selected with the expectation that one of these durations on the new equipment would best "capture" the elusive priming effect.

\section{Method}

\section{Subjects}

Twenty-four members of the University of Massachusetts community were paid to participate in the experiment. They all had normal or corrected-to-normal (wearing contacts) vision and were naive concerning the purpose of the experiment. 


\section{Apparatus}

The sentences used in the study were presented on a Conrac 9317 RGB Auto-Trak display monitor which was interfaced with an ACI 80486 microcomputer using EGA graphics display mode. The sentences were presented in lower case letters (except when capitals were appropriate) which were formed from a 7 x 8 matrix. Subjects were seated approximately 27 inches from the screen and three letters equaled one degree of visual angle. All sentences were displayed on a single line with a maximum length of 42 characters. Luminance of the display was adjusted to a comfortable level and held constant throughout the experiment.

Green and blue input signals produced a cyan display. The display monitor has a P22 phosphor with the characteristic that display blanking results in a drop to $10 \%$ of maximum brightness in $0.06 \mathrm{~ms}$. The display monitor has a vertical scan rate of $130 \mathrm{~Hz}$. Thus, all display changes made in the study (both during saccades and fixations) were accomplished within $7.7 \mathrm{~ms}$.

Subjects' eye movements were monitored via a stanford Research Institute Dual Purkinje Eyetracker (Generation 3) which was also interfaced to the ACI computer. The eyetracker has a resolution of 10 minutes of arc (half a character) and the signal from the eyetracker was sampled every millisecond by the computer. Although viewing was binocular, eye movements were recorded from the right eye. 


\section{Materials}

The sentences used in this experiment were identical to those in Sereno \& Rayner (1992) where they are described in more detail. Briefly, there were 108 experimental sentences, each of which contained a target noun (four or five letters long). For each target noun (e.g., hate), two prime words (equal in length to the target) were identified. One was semantically related (love) and one was unrelated (rule). Conditions in which these primes appear will be referred to as the related (R) condition and the unrelated (U) condition.

There were 27 filler sentences in which a word other than a noun (three to seven letters long) was identified as the "target". Each filler target also had associated R and U primes.

\section{Design}

Across the 108 experimental sentences, three prime durations of 35,30 , and $25 \mathrm{~ms}$ were used. The sentences were blocked (in thirds) by prime duration and each block of sentences was presented at each prime duration. The order of prime duration blocks was counterbalanced across subjects: A third of the subjects received the order 35 , 30 , and $25 \mathrm{~ms}$; another third received the order $30,25,35$ $\mathrm{ms}$; and the remaining third had the order $25,35,30 \mathrm{~ms}$. The two types of primes ( $R$ and $U$ ) were presented equally often within each block of 36 experimental sentences. Thus, there were 6 conditions formed by crossing prime type ( $R$ and 
U) with prime duration (35, 30, and $25 \mathrm{~ms}$ ). Each subject was presented with each target item in only one of the two prime conditions at only one of the three prime durations. This produced 18 possible observations per subject per condition.

\section{Procedure}

When a subject arrived for the experiment, a bite bar was prepared (or obtained from one on file) which was used during the experiment to minimize head movements. Subjects were given a general description of the experimental situation and procedure. They were instructed to read sentences on the CRT as their eye movements were recorded. They were told that they might sometimes notice display changes (i.e., "they might see something flash or see a word change") while they read but that they should try to read as normally as possible. They were also told that they would be asked yes-no questions about the sentences and that they should read for comprehension.

The initial calibration of the eyetracking system generally required about five minutes. Prior to display of a sentence, a series of five boxes (each the size of a single character and equidistant from each other) appeared on the screen, extending from the first to the last character position of a full line of text. During this calibration display, the subject's point of fixation appeared as a small red square on the screen. During a calibration check, subjects were instructed to look at each 
box in succession to verify the accurate recording of eye position. Before the first trial and at other points between trials throughout the experiment, the experimenter checked to see whether subjects maintained proper alignment.

Subjects read six practice sentences to become familiar with the procedure. Before each sentence was presented, the five calibration boxes appeared on the screen. The experimenter checked to ensure that the subject was fixating the first box on the left, gave a ready signal, and then pressed a button to present the sentence. After reading the sentence, the subject pressed a button which cleared the sentence and again displayed the calibration boxes. The sequence then resumed without interruption or the subject was asked a yes-no comprehension question. After the practice sentences, subjects read the 108 experimental sentences which were randomly interspersed with the 27 filler sentences. Questions were asked on approximately one-third of the trials. Subjects had no difficulty answering the questions correctly.

When a sentence was initially presented on the CRT, a string of random letters occupied the target location. An invisible boundary located between the last letter of the word preceding the target and the space before the target was established in each sentence. When an eye movement crossed over this boundary, the computer replaced the random letters with a prime word (see Rayner, 1975, for a description of the boundary technique). This display change 
was accomplished within 0 to $7.7 \mathrm{~ms}$. Because the change took place during the saccade, it was not seen by subjects (it was possible for subjects to preview the random letters if they happened to land near the end of the word preceding the target). The prime word remained in the target location for a specified duration (measured from the onset of the fixation, not from the time the boundary was crossed) and was then replaced by the target noun ${ }^{2}$. Because this change occurred during a fixation rather than a saccade, it was often, although not always, noticed by the subjects. The target noun remained in the target location until the subject finished reading the sentence.

At the end of the experiment, subjects were asked how frequently they noticed a display change and how frequently they could identify the first word (i.e., the prime). They reported being aware of a display change most of the time (from 75-100\% of the time). However, they estimated that they could identify the first word much less frequently (from $0-20 \%$ of the time). Thus, although many were conscious of the change from the prime to the target (during the fixation), they were generally unable to identify the prime word.

${ }^{2}$ A fixation began when the computer detected five successive samples (one every millisecond) such that each was within approximately one-third of a character of the position of the eye as sampled $5 \mathrm{~ms}$ earlier. The fixation was then assumed to begin $9 \mathrm{~ms}$ before this criterion was reached. 


\section{Results}

The target region was considered to include the space before the word as well as the word itself, following the practice of a majority of eye movement studies. Data were excluded from the analyses for the following reasons:

there was a track loss; (2) the reader initially skipped over the target region or completely skipped the target

region; (3) the eyes triggered the boundary but remained on the word before the target (usually the last letter of this word); (4) the time from the boundary crossing to the onset of fixation was less than $4 \mathrm{~ms}^{3} ;$ (5) the onset of the prime followed onset of the fixation; (6) the first fixation on the word was less than $100 \mathrm{~ms}$ or a first pass fixation (i.e., not resulting from a regression) was greater than 800 ms; and (7) a first pass fixation on the target was the last fixation recorded in the sentence. Overall, $25 \%$ of the data were excluded from the analyses.

In Sereno and Rayner (1992), a criterion was established whereby subjects had to have at least $60 \%$ usable data to be included in the study. All 24 subjects in this experiment met this criterion. On average, subjects produced $75 \%$ usable data. With 18 sentences per condition, this meant that on average there were 13.5 observations per subject per condition.

${ }^{3}$ In such cases, the prime was presented for less than the intended duration. 
The data were analyzed both in terms of the first fixation duration and the gaze duration on the target. First fixation duration represents the reader's initial fixation on a word, whether that fixation is the only fixation on the word or whether it is the first of two or more fixations on the word. Gaze duration represents the sum of all consecutive fixations on a word before the reader moves to another word. If the reader fixates a word only once, first fixation duration and gaze duration for that word are identical. Although gaze duration is generally favored in eye movement studies, neither measure is without fault. Because the first fixation measure is applied to instances of words that are immediately refixated (suggesting incomplete processing), it can underestimate processing time. On the other hand, gaze duration may overestimate processing time because it includes instances of refixated words in which additional oculomotor costs beyond processing requirements are involved 4

As in Sereno and Rayner (1992), for each first fixation and gaze duration mean, prime duration was subtracted from fixation time. Thus, fixation time was measured from the onset of the target. These means were then comparable

${ }^{4}$ Sereno (1992) and others (e.g., O'Regan \& Levy-Schoen, 1987) have suggested alternative measures, for example separately analyzing single-fixation and multiple-fixation cases. Because most short content words are usually fixated only once, however, such an analysis would be useful only in limited situations where there is a large number of observations per condition. 
across level of prime duration ${ }^{5}$. Modified first fixation and gaze duration means on the target at the three levels of prime duration across the two prime conditions are displayed in Tables 1 and 2 . Differences between $R$ and $U$ conditions at each level of prime duration also appear in the tables.

Table 1

Mean First Fixation Duration (ms) on the Target Word in Experiment 1

\begin{tabular}{|c|c|c|c|}
\hline $\begin{array}{c}\text { Prime } \\
\text { Duration (ms) }\end{array}$ & $\mathrm{R}^{\mathrm{Pr}}$ & $\begin{array}{r}\text { Type } \\
\mathrm{U} \\
\end{array}$ & $\underline{U-R}$ \\
\hline 35 & 318 & 323 & 5 \\
\hline 30 & 325 & 332 & 7 \\
\hline 25 & 327 & 330 & 3 \\
\hline
\end{tabular}

Note: Prime duration is subtracted from all means.

\section{Table 2}

Mean Gaze Duration (ms) on the Target Word in Experiment 1

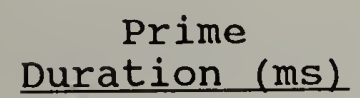

35

30

25

\begin{tabular}{|c|c|c|}
\hline $\mathrm{R}^{\text {Prime }}$ & $\begin{array}{r}\text { Type } \\
\mathrm{U} \\
\end{array}$ & $\underline{U}-$ \\
\hline 341 & 361 & 20 \\
\hline 358 & 359 & 1 \\
\hline 357 & 360 & 3 \\
\hline
\end{tabular}

Note: Prime duration is subtracted from all means.

${ }^{5}$ Subtraction of prime duration assumes that the first few milliseconds of fixation are devoted exclusively to visual encoding of the prime and not to concurrent processing of the prior text. Given that there was only a $10 \mathrm{~ms}$ difference across all levels of prime duration, this was not considered a serious problem. 
The U-R pairwise comparison at each level of prime duration $(35,30,25 \mathrm{~ms})$ was carried out for both the first fixation and gaze duration means. For first fixation duration, none of the U-R comparisons were significant: at 35 and $25 \mathrm{~ms}$, $t s<1$, ps $>0.50$; at $30 \mathrm{~ms}, t_{1}(23)=1.64$ (SE $=4.27), p<0.11$. For gaze duration, at the $35 \mathrm{~ms}$ prime duration, there was a significant $20 \mathrm{~ms}$ advantage for $\mathrm{R}$ versus $U$ prime type, $t_{1}(23)=2.80(S E=7.14), p<0.01$. However, the difference between the $\mathrm{R}$ and $\mathrm{U}$ prime conditions was not significant at either the 30 or $25 \mathrm{~ms}$ prime durations, $t s<1$, ps $>0.75$.

\section{Discussion}

In Experiment 1, a different display monitor (cf. Sereno \& Rayner, 1992) was introduced as part of the apparatus. The purpose of Experiment 1 was to determine which prime duration $(35,30$, or $25 \mathrm{~ms}$ ) on this new monitor yielded significant semantic priming effects similar to those found in sereno and Rayner (1992). $R$ and $U$ primes were presented for the first 35,30 , or $25 \mathrm{~ms}$ of a fixation and were then replaced by the target word. The U-R comparison was made across levels of prime duration for first fixation and gaze duration target means. A significant priming effect -- a $20 \mathrm{~ms}$ advantage for $\mathrm{R}$ versus $\mathrm{U}$ primes -- was obtained in gaze duration at the $35 \mathrm{~ms}$ prime duration level.

It is not clear why a longer prime duration was required in this experiment to obtain priming effects 
compared to that used in sereno and Rayner (1992). On the CRT used in Sereno and Rayner (1992), the nominal prime duration was $30 \mathrm{~ms}$ but the actual duration could range up to $36 \mathrm{~ms}$ (because of a $3 \mathrm{~ms}$ refresh rate combined with the fact that the computer used then was too slow to keep up with the eyetracker sampling rate at all times). The nominal

duration was $35 \mathrm{~ms}$ in the present experiment, but the actual duration ranged from about 35 to about $43 \mathrm{~ms}$ (because the eye could cross the boundary at any point during the $7.7 \mathrm{~ms}$ screen sweep). Thus, it does appear that effective fast priming required a longer prime duration with the Conrac VGA monitor used in the present experiment than with the pointplotting CRT used earlier. The Conrac produced a more legible display as suggested by the shorter fixations found in the present experiment as compared to the earlier one (approximately 355 vs. $375 \mathrm{~ms}$ ). It is not clear why greater clarity would result in a longer required prime duration. Perhaps the greater clarity could lead to more effective masking, but this suggestion is purely speculative.

As mentioned in the prior section, prime duration was subtracted from fixation time to enable comparisons across levels of prime duration. To verify if the effect resulted from priming rather than inhibition, within condition ("vertical") analyses were performed. That is, fixation times at the three prime durations within the $R$ condition were compared and the same was done within the $U$ condition. If there was priming facilitation at the $35 \mathrm{~ms}$ prime 
duration level, then gaze duration at this level of the $R$ condition ( $341 \mathrm{~ms}$ ) should be shorter than gaze duration at the 30 or $25 \mathrm{~ms}$ prime durations ( $358 \mathrm{~ms}, 357 \mathrm{~ms}$ ), and this was the case. If, instead, the priming effect was due to inhibition of the $U$ sense at $35 \mathrm{~ms}$, then gaze duration at this level ( $361 \mathrm{~ms}$ ) should be longer than gaze duration at the 30 or $25 \mathrm{~ms}$ prime durations ( $359 \mathrm{~ms}, 360 \mathrm{~ms}$ ), it was not. Thus, there seemed to be an advantage for semantically related primes presented at $35 \mathrm{~ms}$ versus 30 or $25 \mathrm{~ms}$, while there was no disadvantage for semantically unrelated primes presented at $35 \mathrm{~ms}$ versus 30 or $25 \mathrm{~ms}$. 


\section{CHAPTER III}

\section{EXPERIMENT 2}

Experiment 1 established that, using a different text presentation system than Sereno and Rayner (1992), the prime duration at which reliable priming effects could be obtained was $35 \mathrm{~ms}$. Effective priming at a brief duration was an essential prerequisite for Experiment 2 which involved presenting ambiguous words as primes to targets embedded in different contexts. The basic predictions with regard to models of lexical ambiguity resolution (e.g., selective vs. multiple access), and, hence, lexical processing in general, were as follows: If priming effects were sensitive to a prior context, a selective access (interactive) model would be upheld; if priming effects were indifferent to the prior context, a multiple access (modular) model would be upheld.

Many of the lexical ambiguity studies mentioned in the Introduction have demonstrated that the dominance relationship between alternative senses of an ambiguous word is quite important. This can be seen, for example, in studies that used an isolated word priming task (Simpson \& Burgess, 1985), the cross-modal task (Tabossi, 1988), and the eye movement methodology (Duffy et al., 1988). Evidence from these studies highlights two interrelated aspects of ambiguous words. First, in almost all cases, ambiguous words have one sense that is dominant (D) and one (or more) subordinate $(S)$ sense(s). Second, the strength of the alternative sense of an ambiguous word is critical. That 
is, the relationship between the $D$ and $S$ senses can be strongly biased toward the D meaning (e.g., 95\% D, 5\% S) or it can be more balanced (e.g., 55\% D, 45\% S). Eye movement studies in particular have examined biased and balanced ambiguous words separately. The results from studies which have manipulated meaning dominance show that (1) the D sense becomes available earlier than the $\mathrm{S}$ sense (simpson \& Burgess, 1985) and that (2) the pattern of fixation times on biased compared to balanced words differs depending on the preceding context (neutral or biasing) and the sense (D or S) instantiated by the context (Duffy et al., 1988; Rayner \& Frazier, 1989).

Table 3 shows the 8 conditions of Experiment 2 for the ambiguous prime item bark. The design allows for both the D and $S$ sense of each ambiguous word to be instantiated by the following target word which appears in the second or test sentence of each passage. The target, dogs, instantiates the $D$ sense of bark in conditions 1 and 5, while the target, tree, instantiates the $s$ sense in conditions 3 and 7 . The target sentence is preceded by a context sentence that is either consistent (C) with the instantiated meaning (conditions 1 and 3 ) or inconsistent (I) with the instantiated meaning (conditions 5 and 7). Given the preceding context and the sense instantiated by the target, comparisons are then made between the fixation time on the target when preceded by the $\mathrm{R}$ ambiguous word (bark) compared 


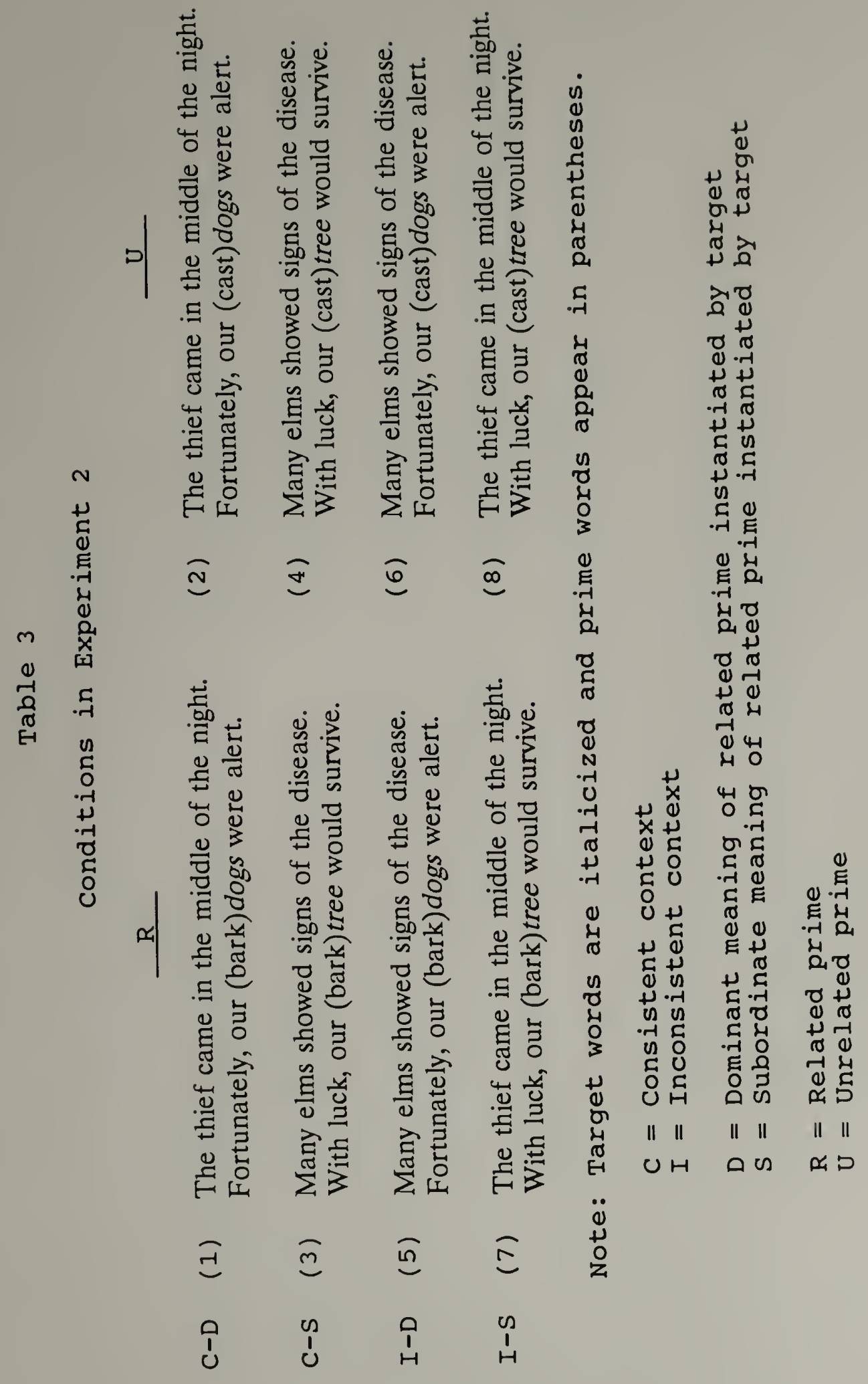


to its fixation time when preceded by a matched $U$ ambiguous control word (cast).

The priming effect in each of the four conditions (C-D, C-S, I-D, and I-S) will be examined in both Biased and Balanced ambiguous words by comparing the $R$ and $U$ conditions. The overall pattern of priming effects that emerges should provide further insight about different types of ambiguous words and the particular sense(s) that may be activated.

\section{Method}

\section{$\underline{\text { Subjects }}$}

Twenty-eight members of the University of Massachusetts community were paid to participate in the experiment. Although 11 of these subjects had participated in Experiment 1, they had never been debriefed about the first experiment. Thus, all were naive to the purpose of the experiment. An additional 11 subjects were run in the experiment but they either failed to achieve the $60 \%$ criterion of usable data (described in Experiment 1 ) or had no observations in one (or more) of the conditions.

\section{Apparatus}

The apparatus was the same as in Experiment 1. Materials

Twenty-eight ambiguous words were chosen. The dominance relationship between $D$ and $S$ senses was calculated for each of the words based on a compiled average of norms collected at the University of Massachusetts (Duffy et al., 
1988; Sereno \& Pacht, 1992) as well as other published norms $^{6}$ (Cramer, 1970; Geis \& Winograd, 1974; Gorfein, Viviani, \& Leddo, 1982; Kausler \& Kollasch, 1970; Nelson, McEvoy, Walling, \& Wheeler, 1980; Perfetti, Lindsey, \& Garson, 1971; Wollen, Cox, Coahran, Shea, \& Kirby, 1980; Yates, 1978). The 28 ambiguous words fell on a continuum such that the $D$ sense of the words ranged from $97 \%$ (table) to $40 \%(b u c k)$. Biased ambiguous words were classified as those having a D sense greater than 75\%, while Balanced words were those having a D sense less than $75 \%$. Of the 28 ambiguous words, 14 were Biased and 14 were Balanced. For Biased words, the component meaning ( $D$ and $S$ ) averages were as follows: $87 \% \mathrm{D}$ (range: $77-97 \%$ ) and $9 \% \mathrm{~S}$ (range: $1-14 \%$ ). For Balanced words, component meaning averages were as follows: $61 \% \mathrm{D}$ (range: $40-74 \%$ ) and $33 \% \mathrm{~S}$ (range: 21-46\%). The mean word frequency, computed from the Francis and Kucera (1982) norms, was 46 per million for Biased words and 21 per million for Balanced words.

For each of the 28 ambiguous words chosen (the $R$ primes), a control word that was ambiguous as well was selected (the $U$ primes). Control words were matched for the dominance relationship among $D$ and $S$ meanings and for overall word frequency. The Biased control words had a mean percentage of $81 \%$ for the D sense (range: $53-97 \%$ ) and $15 \%$

${ }^{6}$ It is assumed that the percentage of subjects preferring a meaning (usually assessed by word association norms) is an accurate measure of the relative frequency of occurrence of that meaning. 
for the $\mathrm{S}$ sense (range: 1-45\%). The Balanced control words had a mean percentage of $54 \%$ for the D sense (range: 37-69\%) and $34 \%$ for the $S$ sense (range: 15-44\%). The mean word frequency was 54 per million for Biased controls and 33 per million for Balanced controls.

A set of 8 sentence pairs or passages was composed for each ambiguous word prime. The set of passages for the ambiguous word bark, with corresponding condition numbers (1 through 8) assigned, are displayed in Table 3 . In all odd condition numbers $(1,3,5$, and 7$)$, bark is the prime and is semantically related to the following target dogs or tree. In even numbered conditions $(2,4,6$, and 8$)$ the prime word is a semantically unrelated control, cast. The U prime is ambiguous as well, with a similar overall word frequency, and a similar interrelation among alternative ( $D$ and $S$ ) senses. The priming effect was always measured by the difference between $R$ and $U$ conditions (U-R) - In effect, there were 4 conditions per item in which such comparisons $(U-R)$ were made: the $C-D, C-S, I-D$, and I-S conditions. The 28 sets of passages are listed in the Appendix. For each set, only the $C$ conditions are listed for $D$ and $S$ senses. The I conditions can be constructed by switching the first or context sentence for the $D$ sense with that for the $s$ sense. The passages are ordered in terms of the strength of the $D$ meaning, so that set 1 (with $R$ prime table) has a $97 \% \mathrm{D}$ meaning and is the most biased, and set 
28 (with $\mathrm{R}$ prime buck) has a $40 \% \mathrm{D}$ meaning and is the most balanced.

Twelve sets (each comprising of 8 passages) of filler passages were constructed in a similar manner to the experimental passages (i.e., inconsistent filler passages were formed from switching the first sentences of consistent passages). In the filler passages, words other than nouns were considered "targets" and were always preceded by semantically unrelated primes. The filler targets were three to seven letters long and could appear in either the first or second sentence (or both) of the passage.

\section{Design}

There were 28 experimental sets of passages. Fourteen used Biased ambiguous primes and 14 used Balanced ambiguous primes. Each passage could appear in 8 possible conditions. The factors were as follows: type of context (Consistent vs. Inconsistent); meaning instantiated by the (unambiguous) target (Dominant vs. Subordinate); and prime type (Related vs. Unrelated). It was possible for a subject to receive 2 of the 8 conditions for a given stimulus set without seeing either the context sentence, the test sentence, or the prime more than once. As the conditions are delineated in Table 3, four different groups of subjects were needed to complete the design for a given stimulus item seeing, for example, conditions 1 and 4,2 and 3,5 and 8 , or 6 and 7 , respectively. Thus, each subject saw 56 experimental passages, with 7 passages in each of the 8 conditions. 
Because there was an equal number of passages that used Biased and Balanced words, subjects received either 3 or 4 passages in each of the 8 conditions for each word type. As with the experimental sets, subjects received two passages from each of the 12 filler sets, and so saw 24 filler passages. Thus, each subject read a total of 80 passages -- 56 experimental passages interspersed with 24

\section{filler passages.}

\section{Procedure}

The procedure was quite similar to that of Experiment 1. The main difference was that the reading task was slightly modified. Subjects were instructed that they would read short passages (two sentences long) and then decide whether the two sentences went together. They were told that sometimes it might be difficult to determine whether the sentences fit together and that it was not unusual if they got a few wrong (they were usually able to justify their mistakes). Subjects were given four practice passages to become accustomed to the procedure. At the beginning of each trial, the words "NEXT PASSAGE" appeared on the screen slightly above the location where each line of text appeared. The experimenter pressed a button and a series of 5 calibration boxes appeared. When the subject fixated the first box on the left, the experimenter pressed a button which removed the boxes and displayed the first sentence. After the subject had finished reading the sentence, she/he pressed a button which cleared the sentence replacing it 
with the calibration boxes. Again the subject fixated the first box and the experimenter presented the second sentence. When the subject pressed the button indicating she/he had read the sentence the question "DO THEY GO TOGETHER?" appeared on the screen with the words "NO" and "YES" displayed under the question. The subject pressed the left button for "NO" responses and the right button for "YES" responses (which corresponded to their spatial location on the screen). Subjects received feedback after every question -- the word "CORRECT" (for $500 \mathrm{~ms}$ ) or "ERROR" (for $1000 \mathrm{~ms}$ ) appeared on the screen. The feedback was immediately followed by "NEXT PASSAGE" and the sequence of events resumed. Subjects were informed that neither the sentence reading nor the time to answer the question were required to be speeded responses. Subjects experienced very little difficulty in answering the questions.

At the end of the experiment, subjects were asked to estimate the percentage of passages in which they saw a display change and the percentage of passages in which they thought they could identify the first word. In general, subjects were much less aware of the changes in this experiment than in Experiment 1 . Subjects reported being able to see a change in about half of the passages (from about 10-95\% of the time). They reported being seldom able to identify the first word (from about $0-15 \%$ of the time). 


\section{Results}

As in Experiment 1, the target region included the space before the word and the word itself. Experiment 2 had far fewer possible data points per subject per condition ( 3 or 4) compared to Experiment 1 (18). To maximize the available data in Experiment 2, trials in which subjects were likely to be attending to the target while not directly fixating it were included. Thus, the region of analysis was expanded by one character to the right of the word (the space after the word) for four-letter words, the rationale being that attention would be directed to the left rather than the right because the reader was denied the normal preview on the prior fixation. For five-letter words, a fixation on the space after the word was included only when (1) it was the first fixation after crossing the boundary and (2) there were no other fixations on the word. In the present experiment, two target items were three letters long. For three-letter words, the space after the word was included in the target region; a fixation on the first letter of the next word was included only when it was the first post-boundary fixation and the word was never refixated.

Data were excluded from the analyses for the same reasons 1isted in Experiment 1 . Overall, $21 \%$ of the data were excluded from the analyses. Thus, on average, subjects produced $79 \%$ usable data. With either 3 or 4 sentences per 
condition, this meant that there were on average 2.4 or 3.2 observations per condition, respectively.

As in Experiment 1, the prime duration (35 ms) was subtracted from fixation time, yielding a modified fixation time which was measured from onset of the target. The 2 (Consistent vs. Inconsistent context) $\times 2$ (Dominant vs. Subordinate meaning) $\times 2$ (Biased vs. Balanced word type) $\times 2$ (Related vs. Unrelated prime type) design gave rise to 16 experimental conditions. Modified first fixation duration and gaze duration means on the target across these 16 possible conditions are presented in Tables 4 and 5 , respectively. All differences between corresponding $R$ and $U$ conditions also appear in the tables.

\section{Table 4}

Mean First Fixation Duration (ms) on the Target Word in Experiment 2

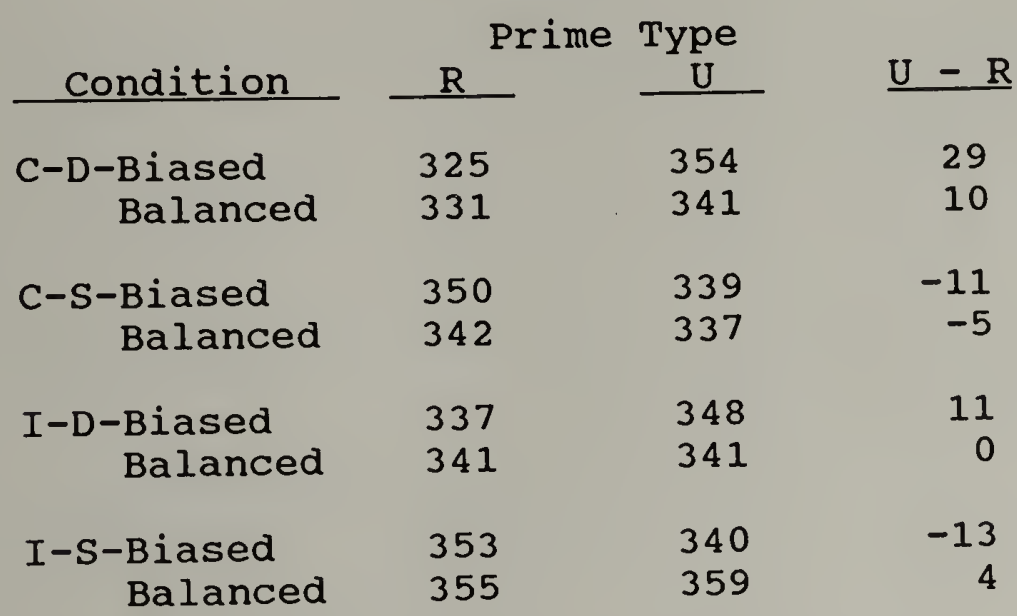

Note: Prime duration is subtracted from all means. 
Table 5

Mean Gaze Duration (ms)

on the Target Word in Experiment 2

\begin{tabular}{|c|c|c|c|}
\hline Condition & $\mathrm{R}^{\mathrm{Pr}}$ & $\begin{array}{c}\text { Type } \\
\mathrm{U}\end{array}$ & $\underline{U}-\underline{R}$ \\
\hline C-D-Biased & 355 & 393 & 38 \\
\hline Balanced & 381 & 382 & 1 \\
\hline C-S-Biased & 371 & 377 & 6 \\
\hline Balanced & 383 & 386 & 3 \\
\hline I-D-Biased & 383 & 380 & -3 \\
\hline Balanced & 372 & 376 & 4 \\
\hline $\begin{array}{r}\text { I-S-Biased } \\
\text { Balanc }\end{array}$ & 381 & 379 & -2 \\
\hline Balanc & 372 & 377 & 5 \\
\hline
\end{tabular}

Note: Prime duration is subtracted from all means.

Planned U-R pairwise comparisons for all conditions (CD-Biased, C-D-Balanced, C-S-Biased, C-S-Balanced, I-DBiased, I-D-Balanced, I-S-Biased, and I-S-Balanced) were carried out for both the first fixation and gaze duration means. For first fixation duration, the only significant effect was the U-R comparison in the C-D-Biased condition: $t_{1}(27)=2.38(\mathrm{SE}=12.38), p<0.05$, and $t_{2}(13)=1.99(\mathrm{SE}$ $=16.08), p<0.07$. All other $\mathrm{U}-\mathrm{R}$ comparisons were nonsignificant $($ all ts $<1)$. For gaze duration, again the only significant effect was the U-R comparison in the C-DBiased condition: $t_{1}(27)=3.71(\mathrm{SE}=10.37), p<0.001$, and $t_{2}(13)=2.46(\mathrm{SE}=17.48), p<0.05$. Likewise, all other U-R comparisons were nonsignificant (all ts $<1$ ). Both measures thus indicated that there was a significant priming effect in only one of the 8 possible conditions -- 
where context instantiated the dominant sense of a biased ambiguous word and that sense was related to a following target (C-D-Biased condition). The effect was $29 \mathrm{~ms}$ for first fixation and $38 \mathrm{~ms}$ for gaze duration.

\section{Discussion}

The purpose of the second experiment was to determine which meaning or meanings, if any, of a lexically ambiguous word are activated in different contexts. The fast priming paradigm developed by Sereno and Rayner (1992) was adapted for this purpose. An ambiguous word was presented as a prime to a target in a sentence during the initial part of the fixation on the target region, and fixation time on the following (unambiguous) target was the dependent measure. The target sentence followed a context sentence that instantiated one or the other of the ambiguous word's senses. By comparing fixation times on targets preceded by Related versus Unrelated ambiguous primes, semantic priming effects contingent on context (Consistent vs. Inconsistent), strength of the meaning instantiated (Dominant vs. Subordinate), and type of ambiguous word (Biased vs. Balanced) were assessed. The prime duration was set at 35 ms, established in Experiment 1 as the duration that rendered semantic priming effects for unambiguous words (with an updated text presentation system).

Experiment 2 showed that semantic priming effects were only obtained when all contributing factors were most favorable -- context was consistent with the dominant sense 
of a biased ambiguous word (C-D-Biased condition). That no priming effects were obtained in all other conditions is of interest as well. The implications of these results for models of lexical ambiguity resolution will be addressed in the General Discussion.

The priming effect in the C-D-Biased condition was significant both in first fixation duration (a $29 \mathrm{~ms}$ effect) and in gaze duration (a $38 \mathrm{~ms}$ effect). The prior fast priming experiments, including both experiments of Sereno and Rayner (1992) and Experiment 1 of the present study, exhibited significant priming effects only in the gaze duration measure (with only suggestive or marginal first fixation effects in Sereno and Rayner (1992)). In Sereno and Rayner (1992) the average effect size was $15 \mathrm{~ms}$ for first fixation and $30 \mathrm{~ms}$ for gaze duration. In Experiment 1 of the present study, the effect size was $5 \mathrm{~ms}$ for first fixation and $20 \mathrm{~ms}$ for gaze duration. In general, gaze duration produces more reliable results. First fixation can underestimate processing time by virtue of the fact that words are sometimes refixated. One possible explanation why there was a first fixation effect in Experiment 2 but not in the other fast priming experiments may have to do with task differences. In Experiment 2, there was a context sentence preceding the target sentence. In addition, having subjects decide whether the two sentences "go together" probably served to heighten contextual awareness. If context does play an early role in activating the proper sense of an 
ambiguous word -- and the results support this since there was priming in the consistent and not the inconsistent context -- then stronger contexts should produce stronger priming. This could be tested by placing the sereno and Rayner (1992) sentences in supportive contexts and examining the pattern of first fixation and gaze durations. 
CHAPTER IV

\section{GENERAL DISCUSSION}

The purpose of the present study was to determine if lexical access can be affected by "higher-level" contextual information. The prevailing evidence (the cross-modal experiments) has favored an autonomous view of lexical processing whereby contextual factors can only influence post-access processing. Various concerns have been raised that cast doubt on the cross-modal findings, including some contrary evidence and possible methodological problems. An alternative eye movement priming paradigm designed by sereno and Rayner (1992) was adapted in this study to examine the early processing of ambiguous words. In this paradigm, fixation duration was the dependent measure and context, prime, and target were presented unimodally in an experimental situation that was temporally more strictly controlled than was possible in prior research.

Reliable semantic priming effects had been obtained in the eye movement priming paradigm by sereno and Rayner (1992). They found that a prime presented for the first 30 ms of a fixation produced priming facilitation in gaze duration (a $28 \mathrm{~ms}$ effect in their first experiment, a $31 \mathrm{~ms}$ effect in their second experiment). Experiment 1 of the present study attempted to replicate this finding using a different text presentation system. Using the same materials as Sereno and Rayner (1992), a significant $20 \mathrm{~ms}$ priming effect was obtained with a $35 \mathrm{~ms}$ prime duration. 
Experiment 2 sought to test competing models of lexical ambiguity resolution with the fast priming technique using the same apparatus as in Experiment 1 . Subjects read short passages consisting of two sentences. The first sentence was a context sentence that instantiated one meaning of an ambiguous word. Separate contexts were constructed for dominant (D) and subordinate (S) senses. A given context, then, had a dual role -- it was consistent (C) with one sense and inconsistent (I) with the other sense. The second or test sentence contained the ambiguous word as a semantically related (R) prime to a succeeding target. The prime was either a Biased $(D>75 \%)$ or a Balanced $(D<75 \%)$ ambiguous word in terms of meaning frequency. Control primes were chosen to have similar lexical properties as the $\mathrm{R}$ prime but were unrelated (U) to the target. Priming effects were measured by comparing fixation time on a target when it was preceded by an $R$ versus a $U$ prime. Such comparisons were made for each of four conditions (C-D, C-S, $I-D$, and I-S) in which Biased and Balanced ambiguous words appeared.

Experiment 2 demonstrated priming only when context was consistent with the dominant sense of a biased ambiguous word (the C-D-Biased condition). There was a significant 38 ms effect $(U-R)$ for this condition in gaze duration. This is the strongest condition for priming -- an ambiguous word primes a target when (1) that word is a Biased ambiguous word, (2) the target is related to its D sense, and (3) the 
prior context supports that sense. No priming effects were obtained for any other conditions. These results bear on two important questions: (1) Which model of lexical ambiguity resolution best accounts for the pattern of data? and (2) What are the implications for the nature of lexical processing in general?

\section{Current Models of Lexical Ambiguity Resolution}

In this section, several models of ambiguity resolution (mentioned in the Introduction) will be considered in turn as candidates to account for the results of Experiment 2 . Each will be briefly presented as somewhat idealized accounts and their acceptability will be assessed. The current models span the interactive-modular spectrum from a selective access (fully interactive) to a multiple access (fully modular) stance. The reordered access and integration models (constructed on the basis of eye movement data) can be considered as somewhat "tempered" interactive and modular models, respectively.

These models can be distinguished on the basis of the present data in the following ways. First, the influence of context serves to distinguish interactive from modular models. If priming occurs only in supportive contexts (in C but not I contexts), an interactive model would be upheld; if priming is insensitive to the context (priming occurs in both $\mathrm{C}$ and I contexts), a modular model would be upheld. Second, the role of meaning dominance distinguishes fully interactive and modular models from tempered ones. If 
priming is dependent on the type of ambiguous word (Biased or Balanced) or the meaning instantiated ( $D$ or $S$ ), then tempered models would be supported; if priming is ubiquitous across these dimensions, the stronger models would be supported.

The selective access model holds that context guides access toward the appropriate sense of an ambiguous word. While both senses may be initially activated, only the contextually appropriate sense is fully accessed. The model predicts that, regardless of the frequency of the instantiated meaning, context selects that meaning. The data, however, do not support such a pure selective access account. While there is no priming in inappropriate (I) contexts, neither is there priming for all appropriate (C) contexts. This model could be modified to take into account meaning dominance, but it then becomes virtually indistinguishable from the reordered access model, which will be examined later.

According to the multiple access model, all senses of an ambiguous word are automatically accessed. Context cannot directly affect lexical processing, but instead operates on the output of the lexical processor to select the appropriate sense. This model predicts that priming effects should be obtained in all conditions ( $C$ and $I$ contexts). The multiple access account must be rejected as well for two reasons. First, there is no evidence of priming in inappropriate contexts, even where the $D$ sense of 
a Biased word is related to the target but context supports the sense (I-D-Biased condition). Second, as in the selective access model, the relative frequency of alternative senses is not incorporated into lexical activation processes. Alternative senses are regarded impartially by the processor. Thus, the data rule out a hard-core multiple access model because the meaning frequency of the instantiated sense as well as its relation to the uninstantiated sense did prove to be relevant -- that is, it was only the $D$ sense of Biased words that produced priming relative to the control.

The integration model can be considered, to a large extent, a modified multiple access model. Alternative senses are activated in order of their meaning frequency and context operates post-lexically on meanings as they become available. Successful integration of one meaning with the prior context can terminate incomplete access procedures of other meanings. The integration model predicts that more dominant meanings should produce greater priming, because they become available first. However, the integration model has trouble accounting for the fact that priming occurred in the C-D-Biased condition but not the I-D-Biased condition. It could possibly account for the effect of $C$ versus $I$ in terms of the difficulty of integrating the prime with the context or the target with the context. However, both of these possibilities have serious difficulties. First, on one hand, it can reasonably be assumed that in the fast 
priming situation, the prime is not integrated with the context. The prime is presented for too brief a time ( 35 ms) for integration to occur. Further, since the prime is not an appropriate part of the message conveyed by the sentence, integrating it with the context would disrupt comprehension. Second, the target, on the other hand, is presumably integrated with context. However, there was no effect of $C$ versus $I$ on the time to read a target preceded by an Unrelated prime word. This finding suggests that the contexts did not affect the difficulty of integrating the target word strongly enough to influence fixation times, making any account in terms of integration of target with context implausible.

The last model to be considered -- the reordered access model -- is also a modified version of a stronger model that incorporates the dominance relationship among alternative meanings. In this model, the alternative senses of an ambiguous word are activated in order of their meaning frequency. Context can affect access by "boosting" the activation of the appropriate sense. There are different consequences depending on the type of ambiguous word. For example, if context instantiates the $\mathrm{S}$ sense of a Biased word, its activation is raised, but the $D$ sense is still strong enough to provide competition whereas, if context instantiates the $S$ sense of a Balanced word, this extra boost may be enough to overcome the base-rate frequency disparity. In terms of the present study, the reordered 
access model would predict that there should have been priming not only in the C-D-Biased condition but in the C-DBalanced condition as well (and perhaps even the C-SBalanced condition). While this model does not completely account for the present data, it comes the closest of all four in doing so and, thus, deserves further development. One aspect of the data that is puzzling with respect to all of the models that have been discussed is that there was no priming in the C-D-Balanced condition. Although Biased and Balanced items were treated separately, it was the case that the relative strength of the $D$ meaning varied within each group: the D meaning component of Biased words ranged from $97 \%$ to $77 \%$ (items $1-14$ in the Appendix); the D component of Balanced words ranged from $74 \%$ to $40 \%$ (items 15-28 in the Appendix). Thus, the strength of the $D$ sense became progressively weaker as item number (1-28) increased. A post-hoc correlation between strength of the $D$ sense and the amount of priming facilitation (U-R) was performed on the item data in the $C-D$ conditions. A significant correlation $(r=0.39, p<0.05)$ was found in gaze duration. This correlation suggests that the relation between the degree of dominance and the amount of priming is a continuous one. It may well be that there is a similar relation between strength of context and amount of priming. While these speculations must await future study, they do have theoretical implications. If the reordered access model is to be salvaged, it must be reconsidered in a way 
that leads to testable predictions. One possible hypothesis that can be drawn from the present pattern of results is that the base-rate activation of the inappropriate sense of the ambiguous prime is the determining factor for effective priming. The only condition in which priming occurred was when the inappropriate sense was the $\mathrm{S}$ sense of a Biased word. A reordered access model would have to include an activation threshold. When the strength of a meaning combines with the strength of the prior context to exceed that threshold, competition between the meanings impedes or negates priming.

\section{Context and Visual Word Recognition}

A skilled reader easily extracts the meanings of individual words of a text. Successful reading, of course, requires more than simple word recognition -- the reader must integrate the meanings of words into a developing text representation which may, in turn, affect the recognition of individual words. Over the past twenty years, numerous studies have investigated the components of visual word recognition from perceptual analysis to semantic interpretation. To isolate and identify factors affecting word recognition, a variety of presentation techniques have been used along with a number of response time measures. While much has been learned, a fine-grained analysis of exactly when and how words are recognized remains elusive. The time course of lexical processing and the degree to which it is form- or content-driven are issues of concern 
for theories of word recognition and also for theories of language comprehension in general.

with the emergence and proliferation of connectionist or parallel distributed processing models (e.g., Kawamoto, 1988; Seidenberg \& McClelland, 1989), certain common assumptions held by traditional theories of lexical knowledge (in particular, the mediation of discrete lexical units) have been re-examined and challenged. In perspective, though, what has been termed the "standard model" of lexical access (Neumann, 1990) has resulted in substantial progress including the introduction of new experimental designs and an enriched understanding of lexical processing. The use of reaction time tasks was an important step in this direction. Hypotheses about the organization of the lexicon can be formulated, for example, if lexical decisions are influenced by word frequency (or if they are not). The priming technique, in conjunction with a reaction time task, has also proved to be effective. Differential priming effects on selected target words provide valuable information about the lexical relationship between prime and target.

The present study represents the application of a new technique -- fast priming during eye fixations in reading -to explore the role of context in the resolution of lexical ambiguity. Foveal placement of prime and target within a single fixation makes it possible to use fixation time on the target as a measure of fast automatic priming. When an 
ambiguous word is presented as a prime to a target in a sentence, either one or both of its senses will be activated. In a biasing context, activation of alternative senses of the prime is measured by an effect (or lack of an effect) on the target. If not providing definitive evidence for a particular model, the present study can be viewed as an empirical contribution clarifying fine details in word recognition.

The use of fixation time as a response time measure of language processing during reading provides certain advantages over other techniques (e.g., lexical decision, naming). Reading is a natural on-line task and eye movements are a normal part of reading. In eye movement studies, "targets" are just like any other word in the text. Readers do not have to make extra-textual decisions about the words they read and, thus, eye movements are relatively free from response bias.

In investigating lexical ambiguity, the eye movement priming paradigm offers several advantages as an alternative to the standard cross-modal task. Fixation time in Experiment 2 (about $380 \mathrm{~ms}$ on average) is shorter than the response time obtained in the cross-modal task (about 500 to $900 \mathrm{~ms})$. Although the fast priming technique involves display changes during reading, the disruption turns out to be rather minimal and, compared to the cross-modal task, contingent attentional demands are greatly reduced. Presenting context, prime, and target in the visual mode 
permits tight experimental control over the time course of processing prime and target. Also, the brief duration of the prime, coupled with fixation time as the response, insure that the task is tapping early lexical processes.

In summary, because of the strict standards imposed by the eye movement priming paradigm, the results obtained here strongly suggest that context can affect lexical processing. Why context is not effective in some circumstances, of course, should be the topic of further investigation. What is important is that there is an early effect under certain favorable conditions. By ruling out oversimplified bottomup or top-down positions, the present findings -- together with similar results from recent studies that emphasize precise temporal measurement and control during lexical processing (e.g., Potter, Moryadas, Abrams, \& Noel, 1993; Van Petten \& Kutas, 1987) -- perhaps reflect a more accurate and complex, albeit less satisfying, picture of brain events during reading. 


\section{APPENDIX}

MATERIALS

\section{$E \times p$ e $r$ i m $n$ t a $1 \quad P$ a $s$ a $g$ e $s$ (targets italicized)}

1. Joan needed more space in her apartment. Her favorite chair would have to go.

Anne was worried about her presentation.

Her most important chart was illegible.

2. Dad had fallen asleep in his chair.

The Russian novel had done the trick.

The high-rise apartment needed renovation.

The fourth floor windows were all broken.

3. The draftsman handled his plan with care.

The fresh ink might get smeared.

The farm hand was proud of his work.

The prize pig would have a new home.

4. The clerk went to deposit the check.

The manager needed money for art supplies.

The flooding caused massive soil erosion.

Some old trees by the river had fallen.

5. Marilyn always misses her appointments.

She forgets what time of day it is.

Shelly loves fruits and nuts.

She puts figs in her cereal.

6. The kittens played tirelessly all day.

They pawed at Mother's wool sweater.

The scouts gathered around the camp fire.

They heard one scary tale after another.

7. The little girl liked to observe insects.
A big black ant captured her attention.

Mary's apartment is under surveillance. A foreign spy may be hiding out with her.

8. Science and astronomy fascinated Charles. He wanted to see the moons around Jupiter.

stan took a job as a waiter in Hollywood. He wanted to be in the movie industry.
P r i m e s

$\mathrm{R} \quad \mathrm{U}$

table party

story plant

pen pot

banks bands

date note

yarn pack

bug $\log$

stars suits 
9. Joe was glad he hadn't played football.

Two friends had broken legs from playing.

The military officer was brought to trial.

He had traded guns for hostages.

10. The continental breakfast left us hungry. We ordered more bread from our waitress.

toast match

The wedding reception was quite lively.

We offered another drink to the groom.

11. Karen would need new basketball shoes. After playing, her little toes were red.

foot pool

Helen measured the length of her office. Her new couch was a whole inch too long.

12. Greg is very competitive and aggressive. He likes a good fight and arm wrestling.

boxer dough

Tom works on the humane treatment of pets.

He examined the crippled puppy carefully.

13. We shall hold another election.

count coach

The final tally will be posted tomorrow.

Many titled people came to the banquet. The wealthy baron brought his mistress.

14. Keith had been out at sea for two weeks. He saw a large ship and he began yelling.

port corn

Bruce was a man with refined taste.

He bought the best wine and cognac.

15. Hindus hold some animals in reverence. The loose cows are safe from harm.

calf cape

Biking has improved my leg muscles.

However, my bruised shin still hurts.

16. We were asked to take many measurements.

ruler quack However, the only scale was broken.

The peasant revolt finally ended.

The new queen had lowered all taxes.

17. The thief came in the middle of the night. bark cast Fortunately, our dogs were alert.

Many elms showed signs of the disease. With luck, our tree would survive. 
18. Carl took music lessons at his church. organ trust He bought a new piano to practice at home.

Jack had to go in for surgery.

Test results from his liver were bad.

19. The park was full of pigeons. Their favorite roost was the statue.

perch pumps

Steve and Linda went fishing.

They caught two nice trout for lunch.

20. The old lady was a fortune teller.

She looked at your hand for a small price.

palm bats

Lana watched the tropical storm roll in.

She saw a tall tree get blown over.

21. Mr. Jeffries was pulled over for DUI.

cell club

A night in the local jail was sobering.

The microscope opened up another universe.

one could observe basic life forms move.

22. Cindy ordered a thick root beer float.

straw shots

she asked for a long spoon to down it.

Laura was new to making scarecrows.

She grabbed some wheat from the wagon.

23. The morning sun streaked into my bedroom.

beam seal

The soft yellow rays warmed my face.

I bought the materials for my tree house.

I got strong wood supports for the base.

24. Tensions mounted as tempers flared. They swung their fists hard at each other.

punch spade

The Halloween party was a great success. our homemade cider was the favorite.

25. One student always gave Miss Day problems. pupil model The rest of her class was well-behaved.

Eleanor had her eyes examined again. Her doctor said her sight had improved.

26. Work on our family room was nearly done. panel range paint on the inside walls was still wet.

The official was charged with harassment. A small group of experts heard the case. 
27. The Wellingtons live in a huge house. Their front lawn is as big as a park.

yard case

The workers measured the room wrong.

The carpet is two extra feet too wide.

28. Dad and I went hunting with great hopes. buck mole We spotted a large deer behind a tree.

Holiday shopping meant giving to charity. We gave some cash to the local shelter. 
Balota, D.A., \& Chumbley, J.I. (1984). Are lexical decisions a good measure of lexical access? The role of word frequency in the neglected decision stage. Journal of Experimental Psychology: Human Perception and Performance, $10,340-357$.

Balota, D.A., Pollatsek, A., \& Rayner, K. (1985). The interaction of contextual constraints and parafoveal visual information in reading. Cognitive Psychology, 17, $364-390$.

Blanchard, H.E., Pollatsek, A., \& Rayner, K. (1989). The acquisition of parafoveal word information in reading. Perception \& Psychophysics, 46, 85-94.

Burgess, C., Tanenhaus, M.K., Seidenberg, M.S. (1989). Context and lexical access: Implications of non-word interference for lexical ambiguity resolution. Journal of Experimental Psychology: Learning, Memory, and cognition, 15, 620-632.

Cramer, P. (1970). A study of homographs. In L. Postman and G. Keppel (Eds.), Norms of word association (pp. 361-382). New York: Academic Press.

Collins, A.M., \& Loftus, E.F. (1975). A spreadingactivation theory of semantic processing. Psychological Review, $82,407-428$.

Dagenbach, D., Carr, T.H., \& Wilhelmsen, A. (1989) . Taskinduced strategies and near-threshold priming: Conscious influences on unconscious perception. Journal of Memory and Language, 28, 412-443.

Dopkins, S. Morris, R.K., \& Rayner, K. (1992) . Lexical ambiguity and eye fixations in reading: A test of competing models of lexical ambiguity resolution. Journal of Memory and Language, 31, 461-477.

Duffy, S.A., Morris, R.K. \& Rayner, K. (1988) • Lexical ambiguity and fixation times in reading. Journal of Memory and Language, $27,429-446$. Ehrlich, S.F., \& Rayner, K. (1981). Contextual effects on
word perception and eye movements during reading. Journal of Verbal Learning and Verbal Behavior, 20 , $641-655$. 
Fischler, I., \& Goodman, G.O. (1978). Latency of associative activation in memory. Journal of

Experimental Psychology: Human Perception and Performance, $\underline{4}, 455-470$.

Fodor, J.A. (1983). Modularity of mind. Cambridge, MA: MIT Press.

Forster, K.I. (1979). Levels of processing and the structure of the language processor. In W.E. Cooper \& E. Walker (Eds.), Sentence processing: Psycholinguistic studies presented to Merrill Garrett (pp. 27-85). Hillsdale, NJ: Erlbaum.

Forster, K.I., \& Davis, C. (1984). Repetition priming and frequency attenuation in lexical access. Journal of Experimental Psychology: Learning, Memory, and cognition, 10, 680-698.

Foss, D.J. (1982). A discourse on semantic priming. Cognitive Psychology, 14, 590-607.

Francis, W.N., \& Kucera, H. (1982). Frequency analysis of English usage: Lexicon and grammar. Boston: Houghton Mifflin.

Geis, M.F., \& Winograd, E. (1974). Norms of semantic encoding variability for fifty homographs. Bulletin of the Psychonomic Society, $3,429-431$.

Glucksberg, S., Kreuz, R.J., \& Rho, S.H. (1986). Context can constrain lexical access: Implications for models of language comprehension. Journal of Experimental Psychology: Learning, Memory, and Cognition, 12, 323335 .

Gorfein, D.S., Viviani, J.M., \& Leddo, J. (1982). Norms as a tool for the study of homography. Memory \& cognition, 10, 503-509.

Hogaboam, T.W., \& Perfetti, C.A. (1975). Lexical ambiguity and sentence comprehension. Journal of Verbal Learning and Verbal Behavior, 14, 265-274.

Inhoff, A.W. (1984) : Two stages of word processing during eye fixations in the reading of prose. Journal of Verbal Learning and Verbal Behavior, 23, 612-624.

Inhoff, A.W. \& Rayner, K. (1986). Parafoveal word processing during eye fixations in reading: Effects of word frequency. Perception \& Psychophysics, 40, 431439 . 
Ishida, T. \& Ikeda, M. (1989). Temporal properties of information extraction in reading studies by a textmask replacement technique. Journal of the optical Society of America A, $\underline{6}, 1624-1632$.

Jacobson, J.Z. (1974). Interaction of similarity to words of visual masks and targets. Journal of Experimental Psychology, 102, 431-434.

Kausler, D.H., \& Kollasch, S.F. (1970). Word associations to homographs. Journal of Verbal Learning and Verbal Behavior, $\underline{9}, 444-449$.

Kawamoto, A.H. (1988). Distributed representations of ambiguous words and their resolution in a connectionist network. In S.I. Small, G.W. Cottrell, \& M.K. Tanenhaus (Eds.), Lexical ambiguity resolution: Perspectives form psycholinguistics, neuropsychology. and artificial intelligence (pp. 195-228). San Mateo, CA: Morgan Kaufmann.

Kiger, J.I., \& Glass, A.L. (1983). The facilitation of lexical decisions by a prime occurring after the target. Memory \& Cognition, 11, 356-365.

Kintsch, W. , \& Mross, E.F. (1985). Context effects in word identification. Journal of Memory and Language, 24 , 336-349.

Marslen-Wilson, W.D., \& Welsh, A. (1978) . Processing interactions and lexical access during word-recognition in continuous speech. Cognitive Psychology, 10, 29-63.

Mayzner, M.S., \& Tresselt, M.E. (1965). Tables of singleletter and digram frequency for various word-length and letter-position combinations. Psychonomic Monograph supplements, $1,13-32$.

Meyer, D.E. \& Schvaneveldt, R.W. (1971). Facilitation in recognizing pairs of words: Evidence of a dependence between retrieval operations. Journal of Experimental psychology, 90, 227-234.

McClelland, J.L. (1987). The case for interactionism in language processing. In M. Coltheart (Ed.), Attention and performance XII: The psychology of reading. Hillsdale, NJ: Erlbaum.

McClelland, J.L., \& Rumelhart, D.E. (1981). An interactive activation model of context effects in letter perception: Part 1. An account of basic findings. Psychological Review, 88, 375-407. 
Morrison, R.E. (1984). Manipulation of stimulus onset delay in reading: Evidence for parallel programming of saccades. Journal of Experimental Psychology: Human Perception and Performance, 16, 268-281.

Morton, J. (1969). Interaction of information in word recognition. Psychological Review, 76, 165-178.

Neisser, U. (1967). Cognitive psychology. New York: Appleton Century-crofts.

Nelson, D.L., McEvoy, C.L., Walling, J.R., \& Wheeler, J.W., Jr. (1980). The University of South Florida homograph norms. Behavior Research Methods \& Instrumentation, $12,16-37$.

Neumann, O. (1990). Lexical access: Some comments on models and metaphors. In D.A. Balota, G.B. Flores d'Arcais, \& K. Rayner (Eds.), Comprehension processes in reading (pp. 165-185). Hillsdale, NJ: Erlbaum.

Onifer, W., \& Swinney, D.A. (1981). Accessing lexical ambiguities during sentence comprehension: Effects of frequency of meaning and contextual bias. Memory \& cognition, 9 , 225-236.

O'Regan, J.K., \& Levy-Schoen, A. (1987). Eye movement strategy and tactics in word recognition and reading. In M. Coltheart (Ed.), Attention and performance XII: The psychology of reading (pp. 363-383). Hillsdale, NJ : Erlbaum.

Pacht, J.M. , \& Rayner, K. (1993). The processing of homophonic homographs during reading: Evidence from eye movement studies. Journal of Psycholinguistic Research, in press.

Perfetti, C.A., Bell, L.C., \& Delaney, S.M. (1988). Automatic (prelexical) phonetic activation in silent word reading: Evidence from backward masking. Journal of Memory and Language, 27, 59-70.

Perfetti, C.A., Lindsey, R. , \& Garson, B. (1971). Association and uncertainty: Norms of association to ambiguous words. Pittsburgh: Learning Research and Development Center, University of Pittsburgh.

Pollatsek, A. , Lesch, M. , Morris, R.K., \& Rayner, K. (1992). phonological codes are used in the integration of information across saccades in word identification and reading. Journal of Experimental Psychology: Human Perception and Performance, $18,148-162$. 
Pollatsek, A., \& Rayner, K. (1990). Eye movements and lexical access in reading. In D.A. Balota, G.B. Flores d'Arcais, \& K. Rayner (Eds.), Comprehension processes in reading (pp. 143-163). Hillsdale, NJ: Erlbaum.

Potter, M.C., Moryadas, A., Abrams, I., \& Noel, A. (1993). Word perception and misperception in context. Journal of Experimental Psychology: Learning, Memory, and Cognition, 19, 3-22.

Prather, P.A., \& Swinney, D.A. (1988). Lexical processing and ambiguity resolution: An autonomous process in an interactive box. In S.I. Small, G.W. Cottrell, \& M.K. Tanenhaus (Eds.), Lexical ambiquity resolution: Perspectives form psycholinguistics, neuropsychology. and artificial intelligence (pp. 289-310). San Mateo, CA: Morgan Kaufmann.

Rayner, K. (1975) . The perceptual span and peripheral cues in reading. Cognitive Psychology, $7,65-81$.

Rayner, K., Balota, D.A., \& Pollatsek, A. (1986). Against parafoveal preprocessing during eye fixations in reading. Canadian Journal of Psychology, 40, 473-483.

Rayner, K., \& Duffy, S.A. (1986). Lexical complexity and fixation times in reading: Effects of word frequency, verb complexity, and lexical ambiguity. Memory \& cognition, 14, 191-201.

Rayner, K. , \& Frazier, L. (1989). Selection mechanisms in reading lexically ambiguous words. Journal of Experimental Psychology: Learning, Memory, and cognition, 15, 779-790.

Rayner, K., Inhoff, A.W., Morrison, R.E., Slowiaczek, M.L., \& Bertera, J.H. (1981). Masking of foveal and parafoveal vision during eye fixations in reading. Journal of Experimental Psychology: Human Perception and Performance, $7,167-179$.

Rayner, K., Pacht, J.M., \& Duffy, S.A. (1993). Effects of prior encounter and discourse bias on the processing of lexically ambiguous words, submitted.

Rayner, K., \& Pollatsek, A. (1989). The psychology of reading. Englewood Cliffs, NJ: Prentice-Hall.

Rayner, K., \& Sereno, S.C. (1993). Eye movements in reading: Psycholinguistic studies. In M.A. Gernsbacher (Ed.), Handbook of Psycholinguistic Research, in press. 
Rayner, K., Sereno, S.C., Morris, R.K., Schmauder, A.R., \& Clifton. C., Jr. (1989). Eye movements and on-line language comprehension processes. Language and cognitive Processes, $\underline{4}$, SI 21-49.

Schustack, M.W., Ehrlich, S.F., \& Rayner, K. (1987). The complexity of contextual facilitation in reading: Local and global influences. Journal of Memory and Language, 26, 322-340.

Seidenberg, M.S., \& McClelland, J.L. (1989). A distributed, developmental model of word recognition and naming. Psychological Review, 96, 523-568.

Seidenberg, M.S., Tanenhaus, M.K., Leiman, J.M. , \& Bienkowski, M. (1982). Automatic access of the meanings of ambiguous words in context: Some limitations of knowledge-based processing. Cognitive Psychology, 14, 489-537.

Sereno, J.A. (1991). Graphemic, associative, and syntactic priming effects at a brief stimulus onset asynchrony in lexical decision and naming. Journal of Experimental Psychology: Learning, Memory, and Cognition, 17, 459477 .

Sereno, S.C. (1992). Early lexical effects when fixating a word in reading. In K. Rayner (Ed.), Eye movements and visual cognition: Scene perception and reading (pp. 304-316). New York: Springer-Verlag.

Sereno, S.C., \& Pacht, J.M. (1992). Unpublished norms of 25 homophonic homographs. University of Massachusetts.

Sereno, S.C., Pacht, J.M. \& Rayner, K. (1992). The effect of meaning frequency on processing lexically ambiguous words: Evidence from eye fixations. Psychological Science, $\underline{3}, 296-300$.

Sereno, S.C., \& Rayner, K. (1992). Fast priming during eye fixations in reading. Journal of Experimental

Psychology: Human Perception and Performance, 18, 173184 .

Simpson, G.B. (1981). Meaning dominance and semantic context in the processing of lexical ambiguity. Journal of Verbal Learning and Verbal Behavior, 20, $120-136$.

Simpson, G.B. (1984). Lexical ambiguity and its role in models of word recognition. Psychological Bulletin, 96, 316-340. 
Simpson, G.B., \& Burgess, C. (1985). Activation and selection processes in the recognition of ambiguous words. Journal of Experimental Psychology: Human Perception and Performance, 11, 28-39.

Simpson, G.B., \& Krueger, M.A. (1991). Selective access of homograph meanings in sentence context. Journal of Memory and Language, 30, 627-643.

St. John, M.F. (1991). Hitting the right pitch: A metaanalysis of the effect of sentence context on lexical access. Newsletter of the Center for Research in Language, UCSD.

Swinney, D.A. (1979). Lexical access during sentence comprehension: (Re)consideration of context effects. Journal of Verbal Learning and Verbal Behavior, 18, 645-659.

Tabossi, P. (1988). Accessing lexical ambiguity in different types of sentential contexts. Journal of Memory and Language, 27, 324-340.

Tanenhaus, M.K., Leiman, J.M., \& Seidenberg, M.S. (1979). Evidence for multiple stages in the processing of ambiguous words in syntactic contexts. Journal of Verbal Learning and Verbal Behavior, 18, 427-440.

Van Petten, C. , \& Kutas, M. (1987). Ambiguous words in context: An event-related potential analysis of the time course of meaning activation. Journal of Memory and Language, $26,188-208$.

Warren, R.E. (1977). Time and the spread of activation in memory. Journal of Experimental Psychology: Human Learning and Memory, $3,458-466$.

Wollen, K.A., Cox, S.D., Coahran, M.M., Shea, D.S., \& Kirby, R.F. (1980). Frequency of occurrence and concreteness ratings of homograph meanings. Behavior Research Methods \& Instrumentation, $\underline{12}, 8-15$.

Yates, J. (1978). Priming dominant and unusual senses of ambiguous words. Memory \& Cognition, $\underline{6}, 636-643$.

Zola, D. (1984). Redundancy and word perception during reading. Perception \& Psychophysics, 36, 277-284. 
